\title{
Do Working Conditions at Older Ages Shape the Health Gradient?
}

\author{
Lauren L. Schmitz ${ }^{\text {a, } 1}$
}

\begin{abstract}
This study examines whether working conditions at the end of workers' careers impact health and contribute to health disparities across occupations. A dynamic panel correlated random effects model is used in conjunction with a rich data set that combines information from the Health and Retirement Study (HRS), expert ratings of job demands from the Occupational Information Network (O*NET), and mid-career earnings records from the Social Security Administration's (SSA) Master Earnings File (MEF). Results reveal a strong relationship between positive aspects of the psychosocial work environment and improved self-reported health status, blood pressure, and cognitive function. However, there is little evidence to suggest that working conditions shape observed health disparities between occupations in the years leading up to retirement.
\end{abstract}

Keywords: Health; Health Disparities; Working Conditions; Aging Workers.

JEL Codes: I1; J1; J81

\footnotetext{
${ }^{a}$ Population Studies Center, University of Michigan. 426 Thompson St., Ann Arbor, MI, 48104, USA. Email: 1schmitz@umich.edu.

${ }^{1}$ Funding: This work was supported by the National Science Foundation (grant no. 1356857); The Center for Retirement Research (project BC14-D3) pursuant to a grant from the U.S. Social Security Administration; and by a National Institute on Aging training grant to the Population Studies Center at the University of Michigan (T32 AG000221). All findings and conclusions are those of the author and do not represent the views of the National Science Foundation, the Social Security Administration, the Center for Retirement Research, or the National Institute on Aging.

The author would like to thank Dalton Conley, Teresa Ghilarducci, Darrick Hamilton, Christopher Ruhm, Joelle Saad-Lessler, Erin Ware, Anthony Webb, and two anonymous reviewers for their comments and support, and Janet Keller and Michael Nolte at the Michigan Center on the Demography of Aging (MiCDA) Data Enclave for their assistance with the HRS restricted data. Any errors are my own.
} 


\section{Introduction}

There is a growing body of evidence that morbidity and mortality are distributed unequally across occupations (e.g. Mackenbach et al., 2008; Marmot et al., 1991). Workers employed in manual occupations report worse health than workers in professional occupations, and their health declines faster with age (Case and Deaton, 2005). Yet little is understood about why occupational health gradients — or differences in health across occupations - exist and how these differences are generated over the life course (Morefield et al., 2011). In particular, as our workforce ages, a growing body of research is concerned with the effect of working conditions on well-being and best practices for integrating the work environment with successful aging (for a review see Zacher, 2015). However, conditional on socioeconomic factors and health behaviors, do working conditions later in life exacerbate the health disparities we observe across occupations at older ages? This study brings together data from ten waves (1992-2010) of the Health and Retirement Study (HRS) with expert ratings of job demands from the Occupational Information Network (O*NET) to examine whether physical demands, environmental hazards, and conditions of the psychosocial work environment impact health and shape health disparities across occupations in the years leading up to retirement.

Examining possible links between workplace factors and health has important implications for retirement age policies and the cost of retiree health care programs. Research on how conditions in the workplace are impacting health is needed to evaluate the efficacy of polices geared towards delaying retirement and increasing labor force participation at older ages. In addition, studying older workers helps us understand the connection between work and health over the life course. If working conditions have a long-term impact on health, investments in interventions earlier in life may mitigate future health expenditures and extend the working life, 
allowing more workers to claim full Social Security benefits and accumulate sufficient savings for retirement.

However, isolating changes in health due to working conditions in the years leading up to retirement is challenging; causal pathways are hard to define and measure and multiple aspects of a worker's job may be impacting health. Additionally, most studies do not adequately deal with the selection bias between job choice and health, making it difficult to draw conclusions regarding causality (Kelly et al., 2011). Workers may select into occupation based on initial wealth, education, and health, or adverse working conditions may trigger behavioral responses that can have compensating or reinforcing effects on health, resulting in nonrandom allocation across occupations (Cottini and Lucifora, 2013; Ravesteijn et al., 2013). Thus, particularly for older workers, estimation must account for factors over the life course that could influence health and selection into jobs.

This study builds on the existing literature on two fronts. First, expert ratings of working conditions that reflect the mix of psychosocial and physical demands found in today's information and service based economy are considered alongside those already identified in industrial settings. Expert ratings of job demands from the U.S. Department of Labor's Occupational Information Network $\left(\mathrm{O}^{*} \mathrm{NET}\right)$ are merged with the HRS to avoid any bias from self-reports of working conditions and to incorporate a much broader range of occupational characteristics into the analysis. Because the O*NET contains data on over 200 characteristics of the work environment, the "work ability" model — the leading model for research on aging and work in the occupational safety and health literature - is used to select working conditions that matter the most for health and labor force attachment at older ages (Ilmarinen and Rantanen, 1999). These include information on physical demands and the physical environment, the 
psychosocial work environment, workplace support for health and functional capacity, and utilization or maintenance of work-related skills.

Second, this study uses a dynamic panel correlated random effects model to estimate more robust correlations between workplace conditions and physical, mental, and cognitive health outcomes. The panel model accounts for a variety of factors that influence health and the decision to work over the life course. In particular, self-reports of childhood health, parental education, and administrative earnings data for jobs held before individuals enter the HRS are incorporated into the empirical model. Past research on occupational health differences at older ages either does not control for childhood health/SES, education, and lifetime earnings, or does not incorporate working conditions into the analysis (e.g. Ferrie et al., 2002; Gueorguieva et al., 2009; Marmot et al., 1997). Therefore, it is not clear whether working conditions have a separate effect on health beyond education, earnings, and occupational status. Incorporating measures of childhood health, lifetime socioeconomic status (SES), and current job demands into the same longitudinal framework makes it possible to assess the relative strength of each factor in shaping health after age 50 while also accounting for the potential feedback between them.

Overall, results show a strong relationship between aspects of the psychosocial work environment and health outcomes at older ages. In particular, the degree of control and influence exercised on the job, or the extent to which jobs allow workers to use their strongest abilities, give them a sense of achievement, independence, variety, authority, creativity, and status, is associated with improved self-reported health status, blood pressure, and cognitive function. A one standard deviation increase in the amount of control and influence exercised on the job is associated with a 2.85 percentage point increase in reporting "excellent" or "very good" healthan effect comparable in magnitude to engaging in vigorous physical exercise three or more times 
per week. However, estimated health trajectories by age and occupational status reveal that even after controlling for working conditions and other life course measures of SES, a significant health gradient between occupations persists-i.e. white collar workers are in significantly better health than blue collar or service workers and these differences remain relatively stable at older ages. In other words, there is little evidence to suggest that working conditions shape observed health disparities between occupations in the years leading up to retirement.

The remainder of the paper is organized as follows. Section 2 provides a review of the literature and its significance. Section 3 describes the primary data sources used in this study. Section 4 explains the methodology, including the measurement and selection of working conditions from the $\mathrm{O}^{*} \mathrm{NET}$, the incorporation of administrative earnings data from the Social Security Administration's Master Earnings File (MEF) into the analysis, and the primary econometric specification. Section 5 discusses the panel results. Section 6 uses model estimates to predict occupational health gradients by age and discusses implications for later retirement and population health. Section 7 concludes.

\section{Review of the Literature and Significance}

A great deal of economic research has focused on socioeconomic-related contributions to health inequality. Differences in health and health behaviors have been linked to income and wealth (Adams et al., 2003; Cutler et al., 2011; Smith, 2007; Smith and Kington, 1997), education (Conti et al., 2010; Cutler and Lleras-Muney, 2010; Lleras-Muney, 2005; Van Kippersluis et al., 2011), occupation (Case and Deaton, 2005; Cottini and Lucifora, 2013; Ravesteijn et al., 2013), and early childhood endowments and investments (Cunha and Heckman, 2007; Currie, 2009; Currie and Almond, 2011). Of course, these factors are highly interrelated, 
making it difficult to unravel their independent influence on health. Evidence from the Whitehall II study, for example, has shown the work environment, social influences outside of work, influences from early life, and health behaviors are all associated with differences in health (Ferrie et al., 2002; Marmot et al., 1997). Particularly with regards to occupation, the potential selection and behavioral effects, along with the scarcity of truly exogenous variation, make it extremely difficult to isolate the independent effect of occupation on health (Dias and O’Donnell, 2013).

To date, the majority of the research on working conditions and health has used crosssectional data to show physically demanding jobs are correlated with lower levels of health (e.g. Bosma et al., 1997; Case and Deaton, 2005; Marmot and Smith, 1997). Longitudinal studies have begun to emerge that link work burdens with the health of workers at a point in time and over their careers (Fletcher et al., 2011; Gueorguieva et al., 2009; Gupta and Kristensen, 2008; Kelly et al., 2011; Robone et al., 2011). An important insight gained from this research is that the cumulative or durable impact of working conditions is potentially more relevant than any contemporaneous outcomes to health later in life. Among these studies, only one examines a large sample of older workers. Using data on the longest-held occupation reported in the HRS, Gueorguieva et al. (2009) find health problems do accumulate over the life course and are systematically different by occupation for older workers. However, it is not clear from this analysis whether working conditions are the primary driver behind occupational differences and if they continue to shape differences in health between occupations at older ages.

Research also tends to focus on a single type or limited set of working conditions, making it impossible to explore clusters of working conditions that matter for health. Much research in the epidemiology, sociology, and occupational safety and health literature has shown physical, 
environmental, and psychosocial aspects of work all have the potential to impact worker health (e.g. Bosma et al., 1997; Cheng et al., 2000; Ilmarinen and Rantanen, 1999; Tuomi et al., 2001). In particular, the decline in manufacturing jobs and the switch to service jobs has increased exposure to psychosocial job stressors (Johnson, 2007; Robone et al., 2011; Wilkinson and Pickett, 2009). More than one aspect of work at a time needs to be studied to see what their joint consequences are for health and how these pathways change over time in a longitudinal framework (Burgard and Lin, 2013). Considering a broad range of working conditions alongside those that have already been identified in more traditional industrial settings may also help pinpoint emerging hazards or specific work-related pathways that influence health in modern service sector and white-collar jobs (Robone et al., 2011).

Additionally, few studies deal with the selection bias that occurs between job choice and health, making it difficult to draw conclusions regarding causality. Particularly at older ages, convincing identification strategies are needed to deal with the possibility that health or SES influences choice of work, or the possibility that a person may self-select into a job with specific working conditions because of their health or SES. For example, being a healthy, robust individual may make it easier to find a job in middle age with better benefits. Workers who are healthier may also search more actively for jobs at that stage, or be promoted without changing jobs, impacting their career trajectory and health status when they enter the HRS. Bias can also arise from self-reports of working conditions. For example, workers who report a tendency within their firm to promote younger individuals in the workplace may have worked in the same place for a long time, signaling that they could not find a better alternative.

To circumvent these endogeneity issues, researchers have used significant adverse, random labor market shocks like job loss or plant closures to investigate subsequent effects on 
health status and mortality (Coile et al., 2012; Falba et al., 2005; Gallo et al., 2004; Gallo et al., 2000; Ruhm, 2000; Strully, 2009; Sullivan and Von Wachter, 2009). Most of these studies use micro-data to compare the health of the employed and the unemployed or aggregate time-series data to investigate the responsiveness of health measures like mortality rates to aggregate economic conditions. However, it is not clear from this literature if less acute labor market conditions could have an effect on the health of older workers over time.

\section{Data}

Table 1 summarizes the three data sources used in this study. Health and employment information is collected from the Health and Retirement Study (HRS), a nationally representative study of Americans over the age of 50 that was launched in 1992. The HRS follows individuals from the time of their entry into the survey until their death. It introduces a new cohort of participants every six years, and interviews current participants every two years. During each two-year interview cycle, the HRS surveys around 20,000 people who represent diverse socioeconomic backgrounds, levels of health status and employment histories. For the purposes of this study, the HRS collects detailed labor market and health data. Occupation and employment information is collected alongside information about chronic illness, functional ability, self-assessed health status, and health related behaviors such as smoking and exercise.

HRS public use data is supplemented with restricted administrative data from the Social Security Administration's (SSA) Master Earnings File (MEF). Specifically, data from the Respondent Cross-Year Detailed Earnings File over the years 1980-2008 is used to capture earnings above and below the SSA taxable maximum. Prior to 1980, the SSA only collected data on earnings below the taxable maximum. Therefore, depending on the cohort, the detailed 
earnings file covers workers' total wages between the ages of 29 and 49 through their final working years in the HRS. ${ }^{2}$ Wages are taken from W2 Box 1, or the "Wages, tips, and other compensation" box on the IRS Form W-2 (i.e. "Total Compensation"). ${ }^{3}$ At the time of this study, the HRS did not have access to the 2010 MEF. To avoid having to drop 2010 from the analysis, the MEF is supplemented with self-reported earnings in 2010. In addition, the detailed files do not contain information on earnings from self-employment (earnings from selfemployment are equal to zero in the detailed file). To ensure a zero value in the detailed file represents a true zero dollar amount, earnings from self-employment in the Respondent CrossYear Summary Earnings File are also included. ${ }^{4}$ All earnings are inflated to 2010 dollars. Expert ratings of job demands are taken from the Occupational Information Network $(\mathrm{O} * \mathrm{NET}) . \mathrm{O} * \mathrm{NET}$ is a comprehensive database of job characteristics produced by the U.S. Department of Labor's Employment and Training Administration and is the leading data source on job demand ratings. It rates 970 plus occupations on more than 200 scales that measure the tasks performed and the characteristics of the physical work environment. O*NET replaced the Dictionary of Occupational Titles (DOT) in 1998 to reflect the shift from a more industrial economy to the mix of knowledge, skills, and abilities used in today's information and service

\footnotetext{
${ }^{2}$ For example, a worker who entered the HRS in 1992 at age 51 was 39 in 1980, while a worker who entered the HRS at age 51 in 1998 was 33 in 1980.

${ }^{3}$ Employee contributions to employer-provided health plans or deferred compensation plans such as a 401(k) or similar plan are not included in the reported amount. Note that "Total Compensation" can contain missing or zero values. A respondent will have a missing value if their employer did not file a W2. Zero values can occur if 1) the amount reported represents a true zero value, 2) an individual is selfemployed (entries for "Net earnings from self-employment" in Schedule SE are not maintained in the detailed files), or 3) records arrive after the usual postings or for certain corrections where the processing focus is on the fields used in determining benefits.

${ }^{4}$ The Respondent Cross-Year Summary Earnings File has information on all covered earnings below the SSA taxable maximum from 1951-2007. This means earnings from self-employment above the taxable maximum are not reported.
} 
based economy.

Table 1. Summary of Data Sources

\begin{tabular}{lccc}
\hline & $\begin{array}{c}\text { Health and } \\
\text { Retirement } \\
\text { Study (HRS) } \\
(\mathbf{1 9 9 2 - 2 0 1 0})\end{array}$ & $\begin{array}{c}\text { Occupational } \\
\text { Information } \\
\text { Network (O*NET) } \\
(\mathbf{1 9 9 8 - 2 0 1 0})\end{array}$ & $\begin{array}{c}\text { SSA Master } \\
\text { Earnings File } \\
\text { (MEF) } \\
(\mathbf{1 9 8 0 - 2 0 0 8})\end{array}$ \\
\hline $\begin{array}{l}\text { Health status, health behaviors, } \\
\text { employment information, } \\
\text { sociodemographic and economic } \\
\text { characteristics }\end{array}$ & $\boldsymbol{}$ & \\
$\begin{array}{l}\text { Expert ratings of job demands } \\
\text { Three digit occupation and industry } \\
\text { codes for current job }\end{array}$ & $\checkmark$ & $\checkmark$ & \\
$\begin{array}{l}\text { Detailed administrative earnings } \\
\text { records }\end{array}$ & & & \\
\hline
\end{tabular}

Restricted three digit occupation codes are used to link the O*NET data with respondents in the HRS. Since the O*NET job characteristics are categorized by the 2000, 2006, or 2009 Standard Occupational Classification (SOC) system, SOC codes are converted to three-digit 2000 Census Occupational Categories to construct a panel that can be merged with the HRS. ${ }^{5}$

Because the HRS uses 1980 Census occupation codes prior to 2006, a consistent set of occupation codes is used to harmonize 1980 and 2000 Census codes. ${ }^{6,7}$ To account for industry effects, restricted three digit industry codes in the HRS are used to harmonize 1980 and 2000 Census industry codes into eight broad categories. See Table 1 in Online Appendix A for details

${ }^{5}$ SOC codes were converted to 2000 Census occupational codes using a coding system provided by the National Crosswalk Service Center: webdata.xwalkcenter.org/ftp/download/xwalks/readme.txt.

${ }^{6}$ A consistent set of occupation codes for Census years 1980 and 2000 is developed in Meyer and Osborne (2005).

${ }^{7}$ In 2010, the HRS shifted to using 2010 Census occupation codes, but provided the corresponding 2000 Census occupation codes as well. 
on the classification of three digit occupational categories, and Online Appendix B for detailed information on how O*NET files were merged and incorporated into the HRS panel.

\section{Methods}

\subsection{Measurement and Selection of Working Conditions}

The O*NET contains information on over 200 characteristics of the work environment. To keep the empirical model parsimonious and capture the most salient pathways between work and health at older ages, working conditions are selected using the "work ability" model. The work ability model is the primary framework for research on aging and work in the occupational safety and health literature, and focuses on workplace attributes that promote good work ability, production, health, and discourage disability claims and premature retirement. The model identifies four key dimensions that predict work ability at older ages, or that prevent disease and disability among older workers and maintain health and labor force attachment in the long run (Tuomi et al., 1997; Tuomi et al., 2001; Ilmarinen et al., 1991):

1) Work demands and the physical environment: This includes negative factors associated with reduced work ability at older ages such as poor work postures, muscular work, harsh physical climate and excessive mental workload, and positive factors associated with improved work ability such as use of knowledge.

2) Work organization and the work community: The psychosocial work environment, including negative factors such as poor management and lack of autonomy, and positive factors, such as utilization of work experience. 
3) Support for healthy lifestyles and functional capacity: Including negative factors such as obesity, smoking, and drinking and positive factors such as time for physical exercise outside work.

4) Maintenance of work-related skills and professional competence: Including job retraining or updating of skills, and opportunities for development and influence at work.

Based on these four dimensions, Table 2 details the five working conditions derived from the O*NET that are used in the analysis. ${ }^{8}$ With the exception of physical demands, all variables are composite indicators. While not exhaustive, the list captures the most important attributes of the physical, environmental, and psychosocial work environment highlighted in the work ability model. The strength of the composite indicators depends on the quality of the variables used in their construction, and factor analysis is used to assess the underlying nature of the data, or to confirm that the underlying dimensions in the HRS-O*NET data set match those hypothesized in the work ability model. ${ }^{9}$ All indicators were normalized to take on a value between 0 and 1 and then standardized for regression analysis. Cronbach's alphas (reported in parenthesis) are used to test the reliability of the indicators. ${ }^{10}$ Table 2 in Online Appendix A contains a detailed

\footnotetext{
${ }^{8} \mathrm{O} * \mathrm{NET}$ assigns a score between one and five for each question, where one indicates the attribute is not important to job performance and five indicates that it is extremely important. All questions were normalized to take values between 0 and 1 .

${ }^{9}$ Analyses was conducted using the principal component estimation procedure. Varimax rotation was applied to produce orthogonal factors. The pattern matrix revealed five uncorrelated principal component factors (see Table 2 in Online Appendix A). All five factors explain $82.45 \%$ of the variance observed (see Table 3 in Online Appendix A). The final indicators were derived from factors with eigenvalues greater than one and include variables with loadings of at least 0.50. Factor 4 was combined with Factor 2 to create the "Environmental Hazard" index due to the similarity of the factor loadings for "exposed to very hot or cold temperatures" and "bright or inadequate lighting" in both factors. Indices were created by summing across indicators and are equally weighted.

${ }^{10}$ Cronbach's alpha is a measure of internal consistency, or how closely related a set of items are as a group. A higher alpha is evidence that the items are highly correlated and are measuring a similar underlying (latent) construct.
} 
breakdown of the $\mathrm{O}^{*}$ NET variables included in each indicator and their corresponding factor loadings.

Table 2. Working Conditions Derived from the O*NET, 1992-2010

Physical demands

(mean $=0.56$; std. dev. $=0.21$ )

\section{Environmental hazards}

(alpha $=0.86 ;$ mean $=0.41 ;$ std. dev. $=0.14$ )

Frequency and impact of decisions

(alpha $=0.92 ;$ mean $=0.79 ;$ std. dev. $=0.10$ )

Supportive management practices

(alpha $=0.88 ;$ mean $=0.63$; std. dev. $=0.07$ )

Degree of control and influence

(alpha $=0.97$; mean $=0.60$; std. dev. $=0.14$ )
Job involves performing physical activities that require considerable use of your arms and legs and moving your whole body, such as climbing, lifting, balancing, walking, stooping, and handling of materials.

Job requires exposure to weather, extreme temperatures, light, noise, contaminants, or cramped spaces.

Worker's decisions have an impact on the image, reputation or financial resources of their employer.

Management is supportive, treats workers fairly, and trains their workers well.

Job allows worker to use their abilities, gives them a sense of achievement, independence, variety, authority, creativity, and status.

The three psychosocial measures derived from the O*NET data ("Impact and Frequency of Decision Making", "Supportive Management Practices", and "Degree of Control and Influence") are comparable with other psychosocial stressors studied in the occupational-health literature. In particular, the Job Demand-Control model (Karasek and Theorell, 1990) argues the primary source of job stress and adverse mental health conditions in the modern workplace comes from the imbalance between job demands and workers' decision latitude in terms of controlling their own activities and skills usage. This suggests, for example, that workplaces with high job demands and low worker autonomy would adversely affect worker health—a finding supported in the literature. Too little task control combined with high levels of demand 
and little workplace support has been associated with a range of health problems, including coronary heart disease (e.g. Bosma et al., 1998). However, the vast majority of these studies use cross-sectional data and subjective worker assessments of job demand and control.

Finally, the third dimension of the work ability model is comprised of individual-level variables that describe whether a person's lifestyle supports health and whether the workplace offers support for a healthy lifestyle. In the work ability framework, the ability to work at older ages depends on the balance between personal resources and work demands. For this third dimension, HRS data on respondents' health behaviors (smoking and exercise) are included in the econometric model alongside data on whether the employer offers health insurance.

\subsection{Lifetime Measures of Health and SES}

Failure to account for factors that influence health and the decision to work over the life course could lead to spurious associations between working conditions and health outcomes at older ages. Literature in the social sciences has linked a web of social, cultural, and demographic factors to health, including factors like educational attainment, income, residence, childhood health, and childhood SES. Research has also found a strong connection between childhood health and adult SES (e.g. Case and Paxson, 2011; Conley and Bennett, 2000; Smith, 2009). Unobservable characteristics such as an individual's ability, risk preference, or personality could also influence health behaviors and selection into jobs. These observable and unobservable characteristics interact with a worker's job history to influence occupational status and working conditions at older ages. For example, occupational trajectories that offer stable job histories, steady increases in status, and healthy working conditions may be determined in early 
adulthood and continue to build on the basis of credentials and workplace performance (Burgard and Lin, 2013).

Self-reports in the HRS of an individual's childhood health, the number of years of education pursued by their mother and father, and the census region they lived in most during their primary schooling years are used to account for observable characteristics that may impact initial selection into occupation (see Table 3 for variable definitions and descriptive statistics). In addition, SSA earnings records are used to account for any significant periods of low pay, churning between jobs, displacement, or time out of the labor force that are correlated with health and occupational status at older ages. Specifically, regression analyses controls for average (log) earnings, volatility of earnings, and the average annual growth rate of earnings at baseline to capture differences in earnings and earnings trajectories before individuals enter the HRS. Earnings volatility is measured as the standard deviation of the arc percentage change in earnings, where the arc percentage change is defined as:

$$
\text { arc percentage change }=100 \times\left(Y_{t}-Y_{t-1}\right) /\left(\left(Y_{t}+Y_{t-1}\right) / 2\right)
$$

The arc percentage change is used because it has the nice features of 1) being symmetric with respect to earnings measures in both years and 2) being defined when either $Y_{t}$ or $Y_{t-1}$ is zero (Dahl et al., 2011). The arc percentage change is not defined when both years are zero, and observations with no earnings in either year are not considered in the calculation. The average annual growth rate of earnings is calculated by taking the mean of the arc percentage change in year-to-year earnings.

While conditioning on childhood characteristics and lifetime earnings may not control for all unobserved factors that impact health and job selection over the life course, the inclusion of 
them strengthens estimated correlations between work and health, and makes it possible to tease apart the impact of prior labor market experiences (to the extent that they are contained in wage) from current conditions. The HRS does not have access to employer information in the MEF, but ideally a complete record of an individual's job history would account for the interaction between the labor demand of firms and the labor supply decisions of workers.

\subsection{HRS Analysis Sample}

Table 3 below shows descriptive statistics for the primary estimation sample, which includes all male full time workers ages 50-65 who are currently working for pay and consented to having their earnings records from the Social Security Administration's MEF linked to their record in the HRS. Results are estimated for men only because health and labor market outcomes vary systematically by gender and because the SSA earnings records of men between 1980 and 2008 are more comparable across HRS cohorts. Concentrating on full time workers circumvents any potential bias that might occur from including workers who are partially retired, which research has shown has positive effects on health (Neuman, 2008). ${ }^{11}$

\footnotetext{
${ }^{11}$ As a robustness check, Table A1 includes results for full time and part time workers. Adding part time workers to the sample does not significantly change the results.
} 
Table 3. Variable Definitions and Descriptive Statistics, HRS Analytic Sample, 1992-2010

\begin{tabular}{|c|c|c|c|c|}
\hline Name & Definition & Obs. & Mean & Std. Dev. \\
\hline \multicolumn{5}{|l|}{ Health Outcomes } \\
\hline Self-Reported Health Status (SRHS) & $\begin{array}{l}1 \text { if reports "excellent" or "very good" health, } 0 \text { if reports "good", "fair", or } \\
\text { "poor" health }\end{array}$ & 7394 & 0.556 & 0.497 \\
\hline Cognitive functioning & $\begin{array}{l}\text { Sum of the immediate and delayed word recall tasks } \\
(0-20 \text {, where } 0 \text { is the worst level, } 20 \text { is the best })\end{array}$ & 6574 & 11.558 & 3.832 \\
\hline $\begin{array}{l}\text { Center for Epidemiological Studies } \\
\text { Depression (CESD) summary score }\end{array}$ & $\begin{array}{l}\text { Sum of self-reported symptoms associated with depression over the past } \\
\text { week }(0-8 \text {, where } 0 \text { is the best level, } 8 \text { is the worst) }\end{array}$ & 5270 & 0.890 & 1.452 \\
\hline High blood pressure & 1 if reports high blood pressure or hypertension, 0 otherwise & 7287 & 0.427 & 0.495 \\
\hline \multicolumn{5}{|l|}{ Income Dynamics (1980-baseline) } \\
\hline Average (log) income & Average (log) earnings at baseline & 7394 & 10.490 & 1.028 \\
\hline Smoke now & 1 if reports currently smoking cigarettes, 0 otherwise & 7394 & 0.216 & 0.412 \\
\hline Exercise & 1 if exercises vigorously three or more times per week, 0 otherwise & 7394 & 0.411 & 0.492 \\
\hline \multicolumn{5}{|l|}{ Childhood demographics } \\
\hline Parents' education & Sum of father's and mother's total years of education & 7394 & 20.087 & 6.884 \\
\hline Childhood health fair or poor & 1 if reports having "fair" or "poor" health as a child, 0 otherwise & 7394 & 0.031 & 0.174 \\
\hline \multicolumn{5}{|l|}{ Census region lived in during school } \\
\hline Northeast & 1 if reports ME, NH, VT, MA, RI, CT, NY, NJ, PA, 0 otherwise & 7394 & 0.164 & 0.371 \\
\hline Midwest & 1 if reports $\mathrm{OH}, \mathrm{IN}, \mathrm{IL}, \mathrm{MI}, \mathrm{WI}, \mathrm{MN}, \mathrm{IA}, \mathrm{MO}, \mathrm{ND}, \mathrm{SD}, \mathrm{NE}, \mathrm{KS}, 0$ otherwise & 7394 & 0.285 & 0.452 \\
\hline South & $\begin{array}{l}1 \text { if reports DE, MD, DC, VA, WV, NC, SC, GA, FL, KY, TN, AL, MS, AR, } \\
\mathrm{LA}, \mathrm{OK}, \mathrm{TX}, \mathrm{AR}, \mathrm{LA}, \mathrm{OK}, \mathrm{TX}, 0 \text { otherwise }\end{array}$ & 7394 & 0.253 & 0.434 \\
\hline \multicolumn{5}{|l|}{ Occupational status } \\
\hline White collar & 1 if occupation is white collar, 0 otherwise & 7394 & 0.526 & 0.499 \\
\hline Blue collar & 1 if occupation is blue collar, 0 otherwise & 7394 & 0.387 & 0.487 \\
\hline Service & 1 if occupation is service, 0 otherwise & 7394 & 0.087 & 0.282 \\
\hline \multicolumn{5}{|l|}{ Industry } \\
\hline Agriculture or mining & 1 if industry is agriculture/mining, 0 otherwise & 7394 & 0.033 & 0.178 \\
\hline Construction & 1 if industry is construction, 0 otherwise & 7394 & 0.074 & 0.261 \\
\hline Public services & 1 if industry is public services, 0 otherwise & 7394 & 0.103 & 0.305 \\
\hline Miscellaneous services & 1 if industry is miscellaneous services, 0 otherwise & 7394 & 0.248 & 0.432 \\
\hline Manufacturing & 1 if industry is manufacturing, 0 otherwise & 7394 & 0.246 & 0.431 \\
\hline Trade & 1 if industry is trade, 0 otherwise & 7394 & 0.129 & 0.336 \\
\hline Finance, Insurance or Real Estate & 1 if industry is FIRE, 0 otherwise & 7394 & 0.051 & 0.219 \\
\hline Public administration & 1 if industry is public administration, 0 otherwise & 7394 & 0.067 & 0.249 \\
\hline \multicolumn{5}{|l|}{ Demographics } \\
\hline Age & Age in survey & 7394 & 58.411 & 3.492 \\
\hline Race & 1 if nonwhite, 0 otherwise & 7394 & 0.115 & 0.319 \\
\hline Veteran status & 1 if reports serving in the military, 0 otherwise & 7394 & 0.494 & 0.500 \\
\hline Marital status & 1 if married, 0 otherwise & 7394 & 0.878 & 0.327 \\
\hline Income & Current individual income (2010 dollars) & 7394 & 65,161 & 83,292 \\
\hline \multicolumn{4}{|l|}{ Education } & 0.383 \\
\hline
\end{tabular}


Restricting the sample to full time workers also ensures a similar degree of exposure to conditions in the workplace and comparable work schedules or hours. In addition, men who worked thirty or more hours per week when initially surveyed in the HRS were more likely to be economically active in the next survey wave than men working fewer than 30 hours, reducing the likelihood of attrition bias due to poor health or early retirement (Aaron and Callan, 2011). The sample is limited to workers at or below the age of 65 to avoid including individuals who claim Medicare Part B benefits at age 65, even if they continue to work, since research has shown an uptick in the self-reported health of previously uninsured individuals in the years after the acquisition of Medicare coverage (McWilliams et al., 2007).

\subsection{Econometric Specification}

A dynamic panel model with correlated random effects is used to estimate the impact of working conditions on self-reported health status (SRHS). Self-reports of health are highly correlated with many objective measures of health, including mortality and many morbidities (Idler and Benyamini, 1997), and can take on five values: "excellent", "very good", "good", "fair", or "poor". To simplify the calculation and presentation of the marginal effects, a binary indicator is created with a value of one if workers report "excellent" or "very good" health, and a value of zero if they report "good", "fair", or "poor" health. ${ }^{12}$

This section outlines the probit specification for SRHS (a similar linear specification is used for other physical, cognitive, and mental health outcomes). This particular model is chosen for several key reasons. First, literature has shown both the persistence of health and unobserved heterogeneity are important factors in explaining the evolution of health (Contoyannis et al.,

\footnotetext{
${ }^{12}$ Putting "good" in the same category as "excellent" and "very good" did not significantly change the results.
} 
2004). Thus, including a lagged dependent variable as a regressor is necessary to separate true state dependence from any spurious dependence caused by unobserved heterogeneity. Second, a correlated random effects model is used because current dynamic panel data estimators for limited dependent variables cannot accommodate fixed effects due to the incidental parameters problem (Lancaster, 2000). Third, because the model is dynamic, the initial condition —or in this case the health status of individuals when they enter the HRS— cannot be treated as exogenous. This would assume, for example, that baseline health status is not correlated with an individual's ability or risk preference - a strong assumption. If any unobserved effects are correlated with working conditions, coefficient estimates will be biased. As a result, the distribution of the unobserved effect is modeled as conditional on health at baseline (Jones et al., 2013; Robone et al., 2011; Wooldridge, 2005)

The econometric model can be motivated by the following latent variable specification:

$$
h_{i t}^{*}=\boldsymbol{w} \boldsymbol{c}_{i t-2} \boldsymbol{\gamma}+\boldsymbol{x}_{i t} \boldsymbol{\beta}+\rho h_{i t-2}+z_{i}+u_{i t} \quad i=1, \ldots, N \text { and } t=2, \ldots, T,
$$

Where $h_{i t}^{*}$ is the unobserved health status of individual $i$ in time period $t, h_{i t-2}$ is health status lagged two years or one wave, $z_{i}$ represents any unobserved heterogeneity and $\boldsymbol{x}$ is a vector of exogenous demographic variables that impact health. The vector $\boldsymbol{w} \boldsymbol{c}_{i t-2}$ includes the working conditions in Table 2 and other direct or indirect aspects of the job that influence health and functional capacity, including hours worked per week, union status, self-employment status, health behaviors (exercise and smoking), health insurance coverage, and industry fixed effects. These are lagged one wave, or two years, to account for any delays in their effects on health. 
The distribution of the unobserved effect $z_{i}$ is modeled as conditional on the initial value of health at baseline, factors that impact job selection over the life course, and the means of any exogenous, continuous time-varying explanatory variables:

$$
\left(z_{i} \mid h_{i 0}, \boldsymbol{c}_{i}, \boldsymbol{j}_{i}, \overline{\boldsymbol{x}}_{\boldsymbol{i}} \sim \operatorname{Normal}\left(\alpha_{0}+\alpha_{1} h_{i 0}+\boldsymbol{c}_{i} \boldsymbol{\alpha}_{2}+\boldsymbol{j}_{i} \boldsymbol{\alpha}_{3}+\overline{\boldsymbol{x}}_{i} \boldsymbol{\alpha}_{4}, \sigma_{a}^{2}\right)\right)
$$

This can also be rewritten as:

$$
z_{i}=\alpha_{0}+\alpha_{1} h_{i 0}+\boldsymbol{c}_{i} \boldsymbol{\alpha}_{2}+\boldsymbol{j}_{i} \boldsymbol{\alpha}_{3}+\overline{\boldsymbol{x}}_{i} \boldsymbol{\alpha}_{4}+a_{i}
$$

The vector $\boldsymbol{c}_{\boldsymbol{i}}$ includes childhood demographic and socioeconomic factors that may impact initial selection into certain occupations, including childhood health, childhood socioeconomic status (parental education), and geographic region lived in most during school (K-12). To control for any significant periods of low pay, churning between jobs, or time out of the labor force that may influence health and occupational status at older ages, the vector $\boldsymbol{j}_{i}$ contains the mean, volatility, and average annual growth rate of an individual's earnings before they enter the HRS. If $a_{i} \mid\left(h_{i 0}, \boldsymbol{c}_{\boldsymbol{i}}, \boldsymbol{j}_{\boldsymbol{i}}, \overline{\boldsymbol{x}}_{\boldsymbol{i}}\right) \sim \operatorname{Normal}\left(0, \sigma_{a}^{2}\right)$ then we can identify the parameters from a probit model with the following response probability:

$$
\Phi\left(\boldsymbol{w} \boldsymbol{c}_{i t-2} \boldsymbol{\gamma}+\boldsymbol{x}_{i t} \boldsymbol{\beta}+\rho h_{i t-2}+\alpha_{0}+\alpha_{1} h_{i 0}+\boldsymbol{c}_{i} \boldsymbol{\alpha}_{2}+\boldsymbol{j}_{i} \boldsymbol{\alpha}_{3}+\overline{\boldsymbol{x}}_{i} \boldsymbol{\alpha}_{4}+a_{i}\right)
$$

By adding $h_{i 0}, \boldsymbol{c}_{\boldsymbol{i}}, \boldsymbol{j}_{\boldsymbol{i}}$, and $\overline{\boldsymbol{x}}_{i}$ in each time period we can estimate the density of $h_{i t}$ given $\left(\boldsymbol{w} \boldsymbol{c}_{\boldsymbol{i t - 2},}, h_{i t-2,}, h_{i 0}, \boldsymbol{c}_{\boldsymbol{i}}, \boldsymbol{j}_{\boldsymbol{i}}, \boldsymbol{x}_{\boldsymbol{i}}, \overline{\boldsymbol{x}}_{\boldsymbol{i}}, \alpha_{0}\right)$ and use a standard random effects ordered probit to estimate the maximum likelihood estimates for $\boldsymbol{\gamma}, \boldsymbol{\beta}, \rho, \alpha_{0}, \alpha_{1}, \boldsymbol{\alpha}_{2}, \boldsymbol{\alpha}_{3}, \boldsymbol{\alpha}_{4}$ and $\sigma_{a}^{2}$. Using random effects is necessary to integrate out the unconditional density of $a_{i}$, or any unobserved effects that could bias estimates. Another advantage of this approach is $\rho$ and $\alpha_{1}$ can be identified, or the 
significance of lagged health status, even after controlling for initial health. After conditioning on initial health, $\rho$ can be interpreted as representing a deviation from some underlying health stock. Therefore, this approach also controls for person-specific unobserved health-related heterogeneity. A limitation of this approach is that it requires specifying a complete model for the unobserved effects. Therefore, results are sensitive to misspecification, and we are relying on the unobserved effect being correctly modeled as conditional on $h_{i 0}, \boldsymbol{c}_{i}, \boldsymbol{j}_{i}$, and $\overline{\boldsymbol{x}}_{i}$.

If certain working conditions have a significant influence on health even after controlling for baseline health status, lagged health status, childhood health, childhood SES, and mid-career earnings trends in each time period, then job demands may contribute to health at older ages. The significance of the working conditions identified will also help uncover the channels through which labor market experiences are affecting health investments at older ages. On the other hand, if working conditions do not explain any of the variation in health status, but earnings history and baseline health are significant, then the cumulative effect of working conditions and SES over the life course may matter more for health than working conditions towards the end of a worker's career.

\section{Results}

\subsection{Self-Reported Health Status}

Table 4 reports estimates of the effect of working conditions on SRHS using pooled ordinary least squares (OLS) and panel data specifications. Column 1 reports results from a pooled OLS model without dynamics and controls for baseline health or lifetime SES, and

Column 2 reports results from a random effects linear probability model (RE LPM) for the same specification. Column 3 reports results from a dynamic panel random effects linear probability model (DPRE LPM) without controls for baseline health and lifetime SES, and Columns 4 and 5 
report both LPM coefficients and probit average partial effects (APE) from the preferred dynamic panel correlated random effects (DPCRE) model outlined in Equation $2 .{ }^{13}$

Results for the DPCRE probit and LPM models in Columns 4 and 5 are very similar and show that initial SRHS and lagged SRHS are strong predictors of current health, indicating both state dependence and unobserved health-related heterogeneity are significant factors in the evolution of health (Contoyannis et al., 2004). Controlling for lagged health, baseline health, and lifetime SES in the panel specifications also reduces both the standard deviation of the individual effect $\left(\sigma_{i}\right)$ and rho, the intra-class correlation of the error term $\left(\sigma_{u}^{2} /\left(1+\sigma_{u}^{2}\right)\right)$, indicating that the DPCRE specification does account for a significant proportion of the error variance attributable to individual time-invariant heterogeneity that may be biasing coefficients in the simpler models. For example, the impact of education and health behaviors on SRHS falls considerably after accounting for person-specific unobserved heterogeneity in the DPCRE models.

Overall, even after controlling for lifetime measures of SES, health behaviors, occupational status, and an extensive list of demographic controls, results reveal that there is a strong association between psychosocial working conditions and health in the years leading up to retirement. In particular, having a high degree of control and influence on the job is associated with the best health outcomes at older ages. A one standard deviation increase in control and influence on the job in the past wave increases the probability of reporting "very good" or "excellent" health by 2.85 percentage points in the current wave - an effect comparable in

\footnotetext{
${ }^{13}$ APEs are used to compare the magnitude of the effects between SRHS and the regressors. Woolridge (2002) shows that computing the partial effect at the observed values of the regressors for each observation and averaging the estimates over the observations provides a consistent estimation of the APE for a dynamic random effects probit model.
} 
magnitude to engaging in vigorous physical exercise three or more times per week. ${ }^{14}$ In other words, occupations that allow men to use their strongest abilities and give them a sense of achievement, independence, variety, authority, creativity, and status are associated with improved health at older ages. The magnitude and significance of this effect persists across all specifications reported in Table 4-i.e. these results are robust to the inclusion of unobserved individual time invariant effects in the DPCRE specification, perhaps because they are not selfreported.

Consistent with the literature, there is a strong association between SES over the life course and SRHS. Childhood SES, educational attainment, and mid-career earnings growth all play a significant role in shaping health at older ages. Of note, a one percent increase in average annual earnings growth during peak earnings years, or between the ages of 23 and 49 depending on the cohort, is associated with a 17.8 percent increase in the probability of reporting “excellent" or "very good" health (Table 4, Column 5). The effect persists even after adding household income flows after age 50 and fluctuations in income at baseline, indicating the trajectory of an individual's earning history may be just as important as the overall level of earnings for health (see Table A1). ${ }^{15}$ This finding is in line with research that has linked downward mobility or unsuccessful career trajectories during peak earnings years with poorer self-reports of mental health in men at age 50 (Tiffin et al., 2005).

\footnotetext{
${ }^{14}$ Although health behaviors are lagged one wave, they could still be considered endogenous in the model if unobserved individual heterogeneity influences both health outcomes and health behaviors. Since excluding health behaviors from the model did not change coefficient estimates, but improved overall model fit, the preferred model includes health behaviors.

${ }^{15}$ To see whether current labor income flows offset declines in health from harsher working conditions, regressions were run including current log transformed wage and salary income (Table A1). Since this specification yielded nearly identical results, the preferred model includes baseline measures of income only to avoid any potential endogeneity from current income flows.
} 


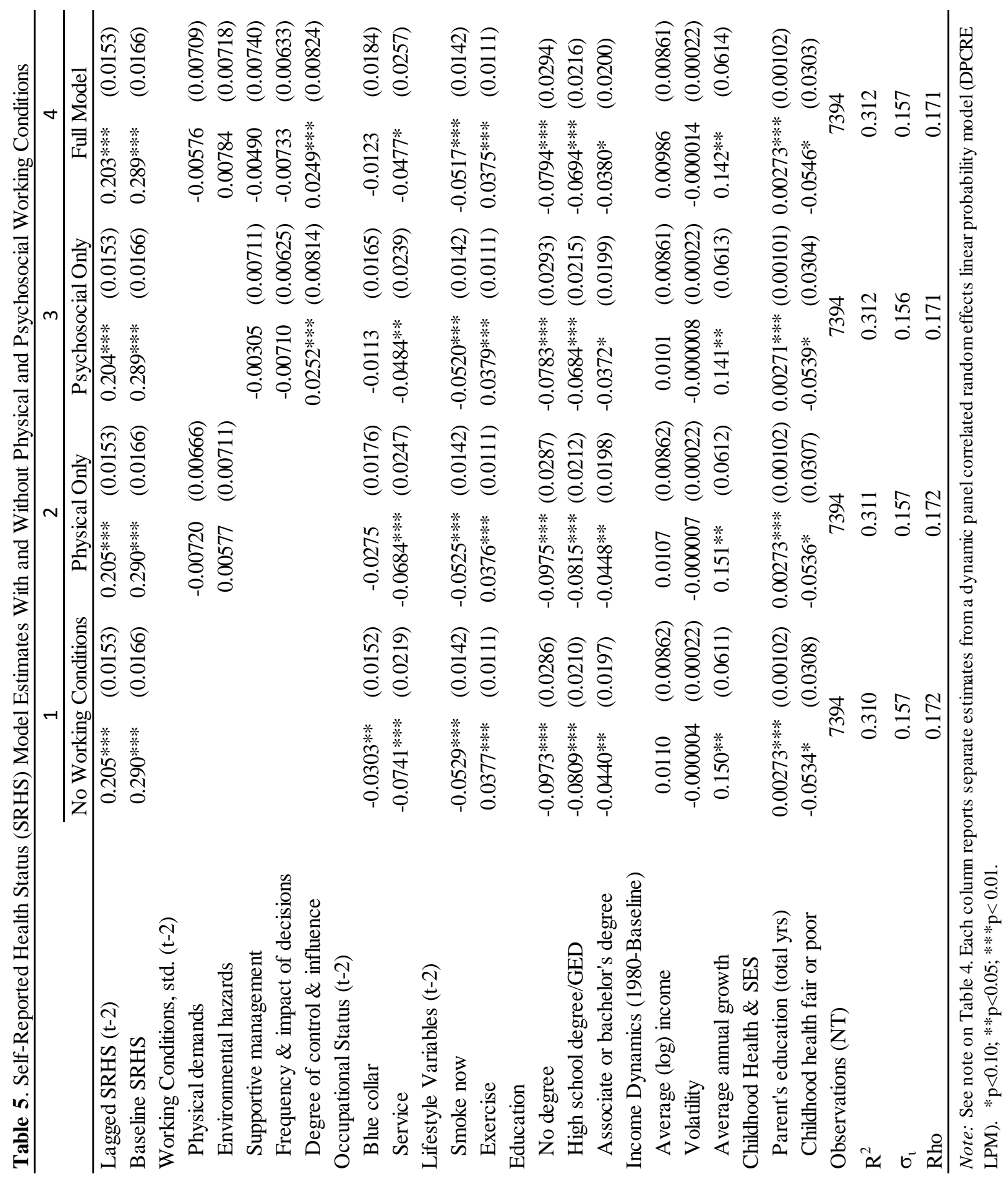




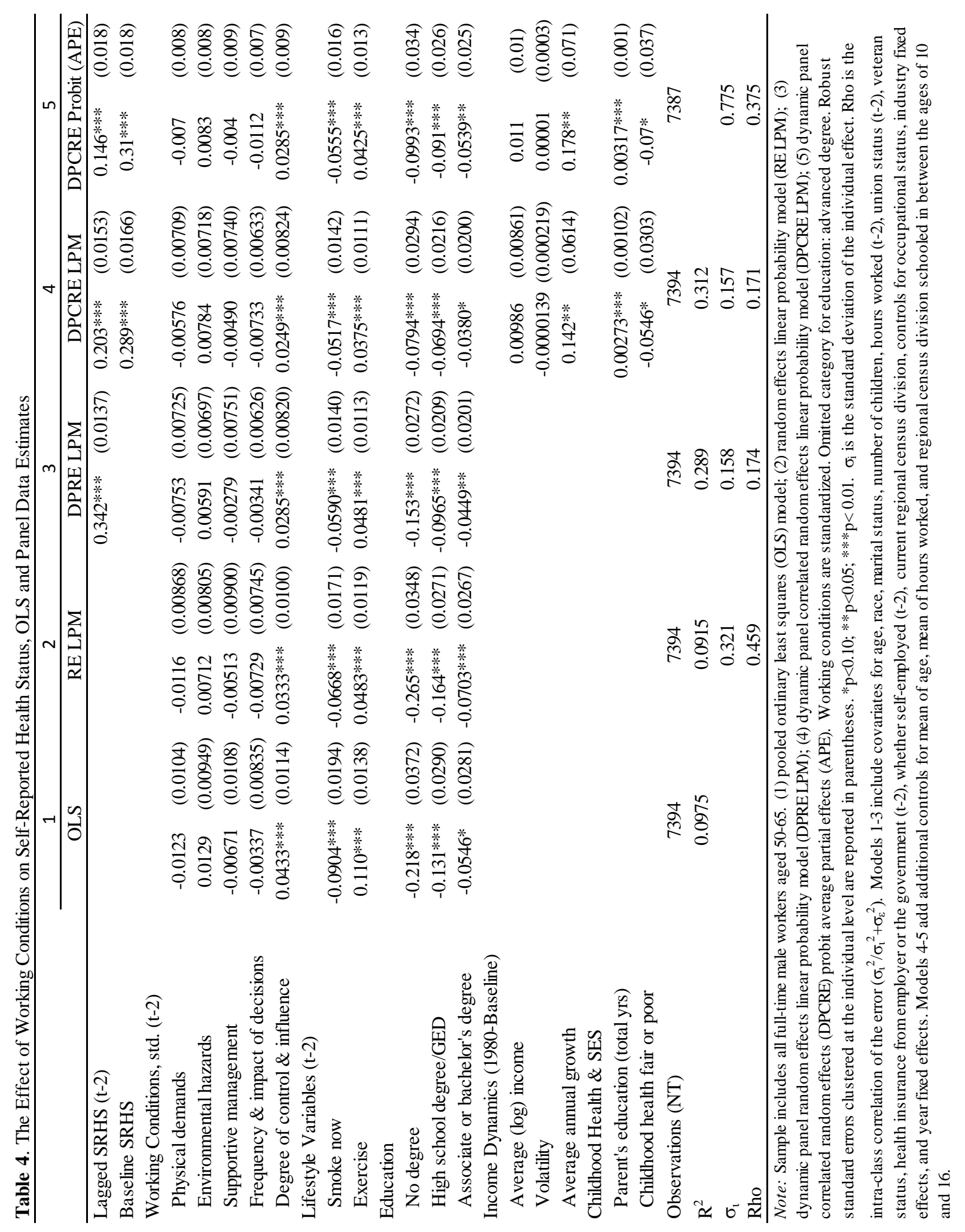


In terms of childhood SES, a one-year increase in parental education is associated with a 0.317 percent increase in the probability of reporting "excellent" or "very good" health and being in fair or poor health as a child reduces the probability of reporting "excellent" or "very good" health by 7 percent, although this effect is only marginally significant.

Table 5 reports results from the DPCRE LPM with and without physical and psychosocial working conditions. Notably, after controlling for all physical and psychosocial O*NET job demands, controls for occupational status (blue collar and service work) are no longer negatively and significantly associated with SRHS compared to white collar workers (the omitted category). This indicates that the Whitehall study and other studies focused solely on the link between occupational status and health may have been capturing unmeasured characteristics of the psychosocial or physical work environment. In addition, the health disadvantage of having no degree or only a high school degree/GED falls by approximately two percentage points compared to workers with an advanced or professional degree after controlling for the psychosocial work environment. Therefore, more control and influence over day-to-day work at older ages, for example, may in part explain the superior health outcomes and longer working lives experienced by workers at the top end of the educational-health gradient.

\subsection{Tests for Attrition Bias}

While this estimation strategy presents fairly robust correlations between working conditions and health, attrition bias due to poor health or the retirement decision (whereby the healthier work longer) could be influencing results. Men who leave the sample early, or retire at or before the Social Security Early Eligibility Age (EEA) of 62, tend to be in worse health and 
are less likely to be college educated or offered positions with more desirable working conditions (e.g. Card et al., 2014; Hurd et al., 2004). Healthier workers that are more educated may also self-select in jobs with better working conditions at older ages, or offered positions with better compensation packages. In addition, it is possible that results may be biased due to mortality selection, particularly if workers with worse working conditions are in poorer health and, as a result, die and drop out of the sample at a faster rate than workers with more desirable work environments (e.g. Case and Deaton, 2005). In all these cases, estimates are likely to be biased upwards and will not capture the causal effect of workplace demands on health in the years leading up to retirement.

To test for attrition bias, variables that reflect the pattern of survey response are constructed for each respondent and included in the model to test for statistical associations between nonresponse and health (Jones et al., 2013; Verbeek and Nijman, 1992). These include survey response indicators for 1 ) the total number of waves a respondent is in the sample $(T) ; 2$ ) whether the respondent appears in all waves; 3 ) whether the respondent appears in the next wave; and 4) whether the respondent dies between the current interview and next sample wave. ${ }^{16}$ If nonresponse is random, these patterns should not be associated with health. Wald tests fail to reject the null hypothesis $(\beta=0)$ for coefficients on the total number of waves the respondent is in the sample, whether the respondent appears in the next wave, and whether the respondent drops out in the next wave due to death. Furthermore, with regards to mortality selection, Kaplan-Meier survival estimates by occupational status for all male workers in the HRS reveal that conditional on survival at age 50 , age differences in mortality by occupational status do not

\footnotetext{
${ }^{16}$ Only 52 workers leave the sample due to death. Of these, 21 are white collar workers, 25 are blue collar workers, and 6 are service workers-i.e. non-response due to death is not disproportionally concentrated among blue collar or service workers.
} 
begin to diverge until after age 70 (see Figure A1 in the Appendix). ${ }^{17}$ Since workers in the analytic sample are only observed until age 65 , this is further evidence that results are not subject to dynamic selection with respect to mortality. However, tests for attrition bias do reject the null hypothesis $(p<0.05)$ for whether the respondent appears in all waves, indicating health-related attrition may still be influencing results.

To assess this further, Table A2 in the Appendix compares estimates from separate models that stratify by the number of waves workers appear in the sample. The specification in Column 1 includes workers who only appear in one or two waves of the sample, Column 2 includes workers who appear in one to six waves of the sample, and Column 3 controls for individuals who appear in all eight waves. Results are fairly consistent across models and if anything show a slight increase in the impact of psychosocial working conditions on SRHS for workers who appear in only one or two waves of the sample. ${ }^{18}$ In other words, if anything it appears coefficients on the $\mathrm{O} *$ NET variables are biased downwards from sample attrition, meaning the estimates reported from the preferred DPCRE model are likely on the conservative side.

\subsection{Other Physical, Mental, and Cognitive Health Outcomes}

To further elucidate pathways between occupation and health after age 50, associations between working conditions and stress related physical, mental, and cognitive health outcomes are also explored. Targeting specific outcomes may lead to a better understanding of how

\footnotetext{
${ }^{17}$ Figure A1 in the Appendix shows Kaplan-Meier survival estimates by occupational status for all male workers in the HRS between 1992 and 2010 (number of deaths=4,865).

${ }^{18}$ The gradual decrease in coefficient estimates on working conditions as the number of sample waves increases holds for any combination of response waves (e.g. one to three waves, one to four waves, one to five waves, etc.). Results are available from the author upon request.
} 
occupational health gradients are generated. In addition, it is possible SRHS is itself endogenous to occupation, as previous work has shown it is endogenous to labor market status (e.g. Bound, et al., 2001; Bound et al., 2010). Occupation may affect how workers report their health, how well they monitor their health, or the frequency of doctor visits. SRHS is also subject to various sources and degrees of measurement error (see Currie and Madrian, 1999 for a review), is subject to reference bias (Groot, 2000), and cultural and other differences in cut points between categories (Jürges, 2007).

As a result, a similar linear specification is estimated to examine pathways between working conditions and stress-related cardiovascular, cognitive, and mental health outcomes (see Table 3 for variable definitions). These include: 1) doctor diagnosed heart disease, 2) doctor diagnosed high blood pressure or hypertension, 3) cognitive functioning (total word recall summary score), and 4) depression (Center for Epidemiological Studies-Depression (CESD) summary score). For these health outcomes, the same dynamic panel correlated random effects model and all related assumptions associated with Equation 2 are used with the exception that $h_{i t}^{*}$ represents an observed, rather than a latent, variable. ${ }^{19}$ Results from linear models for the incidence of doctor-diagnosed heart disease or high blood pressure (a dichotomous indicator) are reported because the marginal effects are similar to the average partial effects estimated from analogous probit specifications.

Results are reported in Table 6. As with SRHS, the psychosocial work environment is associated with better physical and cognitive health outcomes at older ages. The degree of control and influence exercised on the job is correlated with improved cognitive function and hypertension. In line with other studies that find hypertension is associated with psychological

\footnotetext{
${ }^{19}$ A correlated random effects model is used as opposed to an Arellano-Bond specification for all linear health outcomes because older workers are only in the sample for an average of three waves (including the baseline wave), making the use of additional lags as instruments infeasible.
} 
stress and lower occupational status (e.g. Levenstein et al., 2001; Markovitz et al., 2004; Wiernik et al., 2013), results show a one standard deviation increase in control and influence on the job lowers the probability of being diagnosed with high blood pressure by 0.89 percentage points. As a basis of comparison, this is approximately one percentage point less than the impact of engaging in physical exercise three or more times per week. Likewise, jobs that require workers to make frequent, high stakes decisions are associated with improved cognitive function. A one standard deviation increase in high stakes decision making on the job is associated with a 0.13 increase in the 20 point word recall summary score. This is consistent with prior empirical work that has demonstrated the long-term cognitive benefits of being involved in work with high levels of mental demand (e.g. Finkel et al., 2009; Fisher et al., 2014; Potter et al., 2008). Across the board, there is no evidence that physical demands or environmental hazards are associated with stress-related cardiovascular, cognitive, or mental health outcomes at older ages.

As with SRHS, education and earnings history exert the strongest influence on cognitive function and depression. Obtaining an advanced or professional degree and having higher average mid-career earnings is highly correlated with improved cognitive function, and years of parental education are associated with lower CESD summary scores. Unsurprisingly, rigorous physical activity three or more times per week in the last wave is associated with lower blood pressure and CESD summary scores, while smoking is the only significant factor associated with heart disease. 


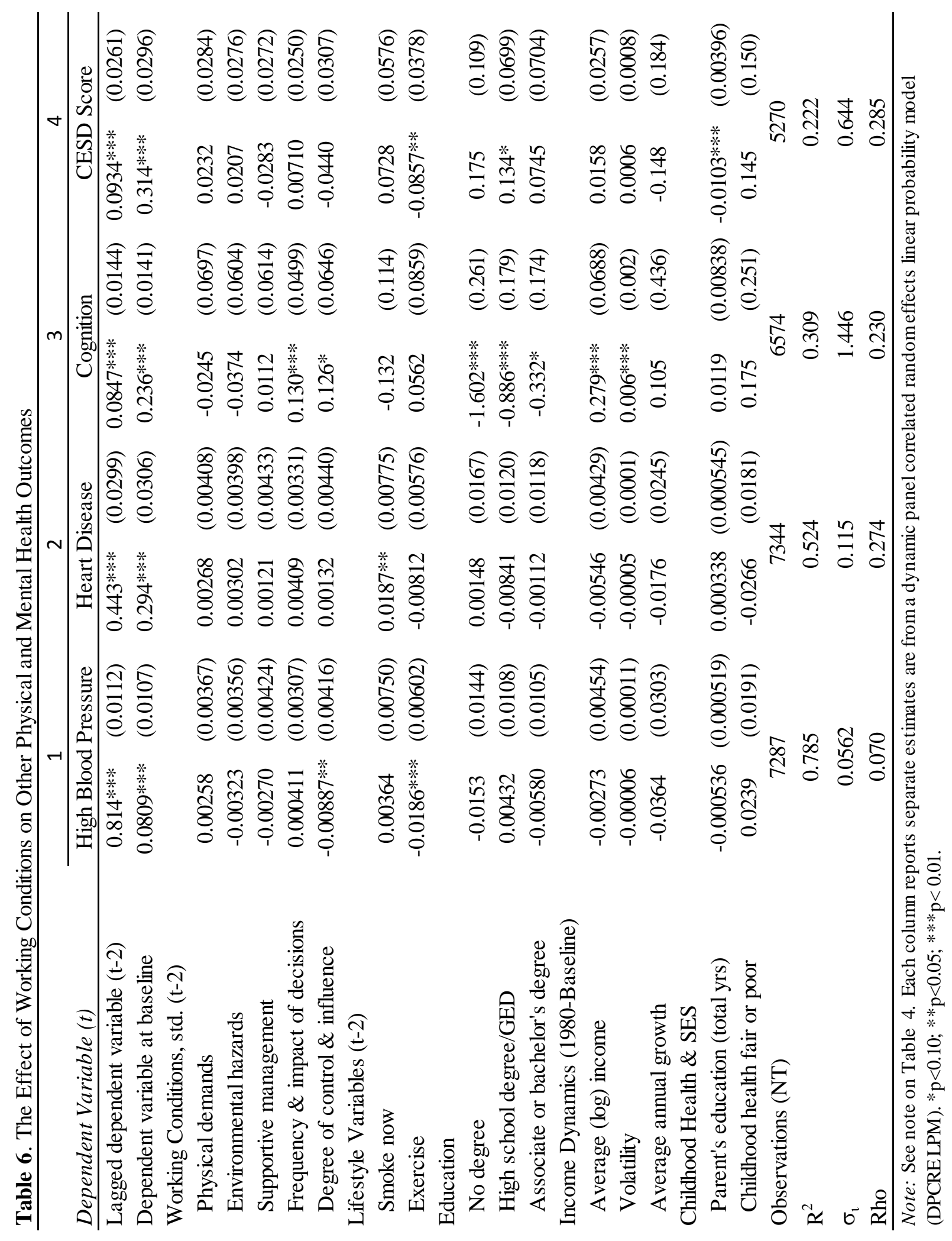




\section{Health Trajectories by Age and Occupational Status}

So far, results have shown that conditions of the psychosocial work environment are associated with better health outcomes at older ages. However, do these conditions exacerbate the health disparities we observe across occupations or are occupational health gradients more or less fixed at older ages? To answer this question, parameter estimates from the DPCRE LPM model are used to simulate trajectories of SRHS for all workers between the ages of 50 and 70 by occupational status:

$$
\hat{h}_{a_{\omega}}=\frac{1}{N T} \sum_{i=1}^{N} \sum_{t=2}^{T} F\left(\hat{\theta}_{\omega} a+\boldsymbol{w} \boldsymbol{c}_{i t-2} \widehat{\boldsymbol{\gamma}}_{\omega}+\boldsymbol{x}_{i t} \widehat{\boldsymbol{\beta}}_{\omega}+\hat{\rho}_{\omega} h_{i t-2}\right) i=1, \ldots, N, t=2, \ldots, T,
$$

Where $\hat{h}_{a_{\omega}}$ is the average predicted probability of reporting "excellent" or "very good" health for a given occupational status $(\omega)$ at a particular age $(a=50, \ldots, 70)$, holding all other model covariates at their sample values. Fig. 1 below reports the predicted probabilities by occupational status with 95 percent confidence intervals. Average predicted probabilities are estimated for blue collar and service workers combined due to the similarity of the estimates. Individual random effects are not included in the estimation.

The graph shows statistically significant differences in SRHS between white collar and blue collar or service workers at all ages. White collar workers are on average 17.5 percent more likely to report "excellent" or "very good" health between the ages of 50 and 70 compared to blue collar or service workers. However, even after controlling for working conditions, there is little evidence that health disparities between occupations narrow or widen over time. In other words, results are consistent with a past studies that have found systematic differences in health 
by occupational status tend to stabilize at older ages (Ferrie et al., 2002; Gueorguieva et al., 2009; Marmot et al., 1997). ${ }^{20}$

Figure 1. Predicted SRHS by Occupational Status and Age

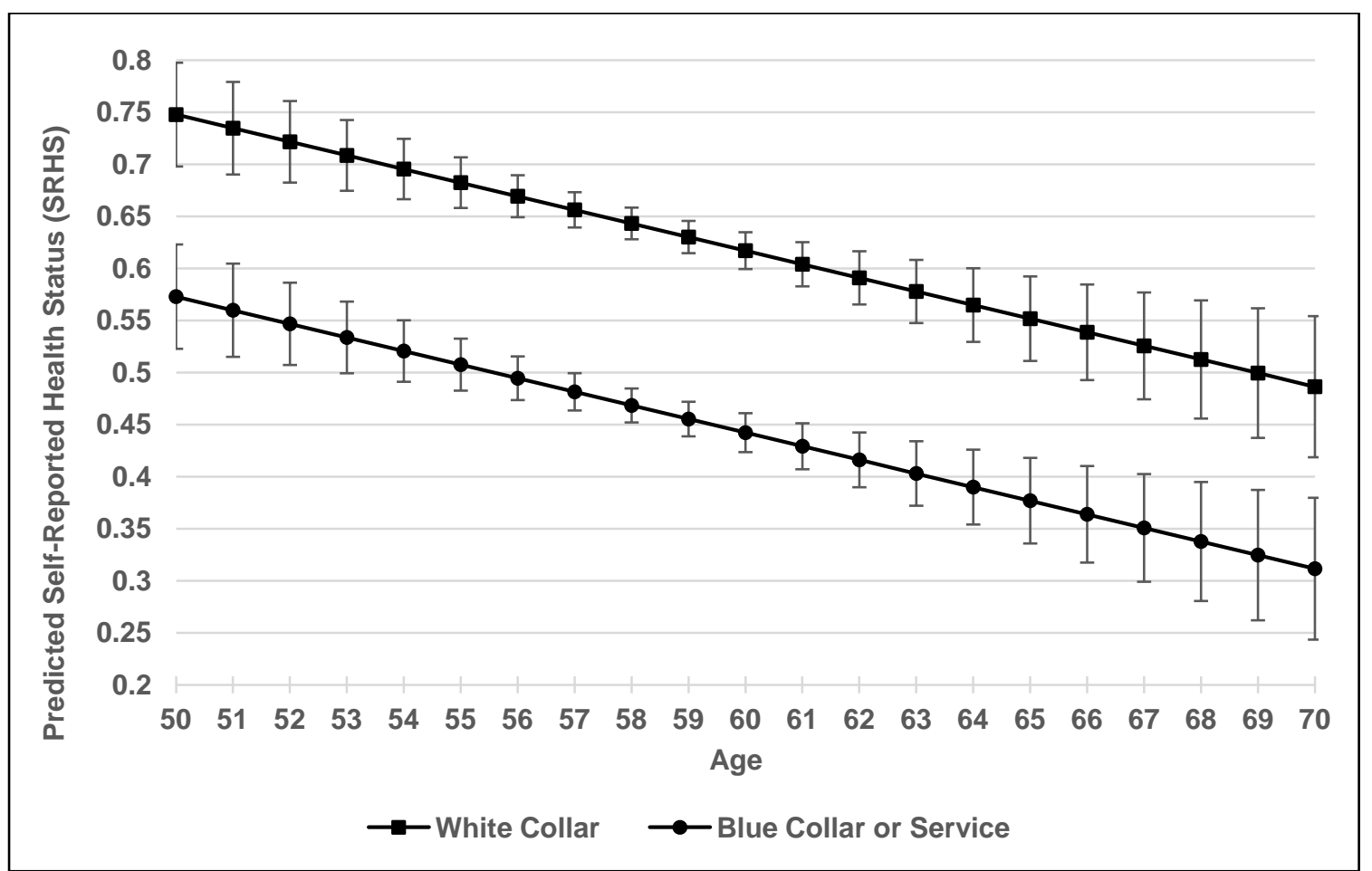

Additionally, the results presented in Fig. 1 suggest policies that seek to close the projected shortfall in Old-Age, Survivors, and Disability Insurance (OASDI) trust funds by boosting labor force participation at older ages need to take into account the fixed nature of the occupational health gradient. Specifically, given fixed health differences between occupations at older ages, it is important to consider how an increase in the Social Security "normal" retirement age (NRA) from 66 to 70 would affect the occupational composition of the workforce and the

\footnotetext{
${ }^{20}$ To see if dynamic selection with respect to mortality affects the simulations in Figure 1 or Table 7 , as a robustness check, model simulations were recalculated for individuals who do not leave the sample due to death or premature mortality. Estimates were comparable across both samples and are available from the author upon request.
} 
subsequent health of the elderly population. ${ }^{21}$ To illustrate how increasing the NRA to 70 would affect population health, Table 7 below compares actual and predicted health by occupational status and age for full time male workers aged 62-70. "Actual” SRHS and corresponding sample size estimates are obtained from pooled averages of six waves of HRS data (2000-2010). "Predicted" SRHS is estimated from Equation 6 and corresponds to the predicted probabilities reported in Fig. 1. Population weighted "predicted" means are calculated using the predicted probabilities and the average (pooled) sample size for male workers who report working fulltime before they are eligible for early Social Security claiming at age $61(\mathrm{~N}=408,360)$. The difference between the predicted and actual population means is an estimate of the change in worker health that would occur if the occupational composition of the workforce at age 61 were held fixed until age 70.

Estimates show the health of the male labor force over age 61 would fall by an average of 6.5 percentage points per year if workers employed at age 61 continued working full-time until they were eligible for full Social Security benefits at age 70. Broken down by occupational status, population health would decline by an average of five percentage points per year for white collar workers and eight percentage points per year for blue collar or service workers. Although these calculations are a rough approximation and rely on the unrealistic assumption that all workers would have the capacity, need, and employment opportunities to continue working until age 70 , they illustrate that policy nudges to extend the working life may increase labor supply but at a cost to worker health—particularly for workers in blue collar or service occupations.

\footnotetext{
${ }^{21}$ Currently, the U.S. Social Security NRA is 66 but will reach 67 for workers born after 1960. The early eligibility age (EEA) has remained fixed at 62 and is still the youngest age at which retirement benefits are paid. Individuals who claim at 62 currently receive 75 percent of the age- 66 benefit, and each year the NRA retirement age is increased benefits are reduced across the board for new claimants by eight percent. Thus, raising the NRA to 70 has been proposed as a way to both increase labor force supply and close the Social Security funding gap (Aaron, 2013).
} 
Thus, any reduction in the OASDI trust fund gap from an increase in labor force participation at older ages must be weighed against possible declines in worker health and higher health care costs.

Table 7. Actual and Predicted SRHS by Occupational Status and Age

\begin{tabular}{|c|c|c|c|c|c|c|c|c|c|c|c|}
\hline & \multicolumn{4}{|c|}{ Predicted } & \multicolumn{4}{|c|}{ Actual } & & & \\
\hline & \multicolumn{2}{|c|}{ White Collar } & \multicolumn{2}{|c|}{$\begin{array}{l}\text { Blue Collar or } \\
\text { Service }\end{array}$} & \multicolumn{2}{|c|}{ White Collar } & \multicolumn{2}{|c|}{$\begin{array}{l}\text { Blue Collar or } \\
\text { Service }\end{array}$} & \multicolumn{3}{|c|}{$\begin{array}{l}\text { Population Weighted } \\
\text { Mean (SRHS) }\end{array}$} \\
\hline Age & SRHS & $\begin{array}{c}\mathrm{N} \\
(\operatorname{age}=61)\end{array}$ & SRHS & $\begin{array}{c}\mathrm{N} \\
(\operatorname{age}=61)\end{array}$ & SRHS & $\mathrm{N}$ & SRHS & $\mathrm{N}$ & Predicted & Actual & Diff. \\
\hline 62 & 0.593 & 408,360 & 0.416 & 321,455 & 0.651 & 300 & 0.451 & 237 & 0.515 & 0.563 & -0.048 \\
\hline 63 & 0.581 & 408,360 & 0.403 & 321,455 & 0.645 & 263,951 & 0.435 & 196,504 & 0.503 & 0.555 & -0.053 \\
\hline 64 & 0.568 & 408,360 & 0.390 & 321,455 & 0.621 & 239,833 & 0.355 & 156,731 & 0.490 & 0.516 & -0.026 \\
\hline 65 & 0.556 & 408,360 & 0.377 & 321,455 & 0.584 & 143,972 & 0.5 & 141,991 & 0.477 & 0.542 & -0.065 \\
\hline 66 & 0.543 & 408,360 & 0.364 & 321,455 & 0.625 & 129,689 & 0.417 & 97,238 & 0.464 & 0.536 & -0.072 \\
\hline 67 & 0.531 & 408,360 & 0.351 & 321,455 & 0.54 & 118,103 & 0.547 & 79,953 & 0.452 & 0.543 & -0.091 \\
\hline 68 & 0.518 & 408,360 & 0.338 & 321,455 & 0.527 & 81,303 & 0.411 & 67,897 & 0.439 & 0.474 & -0.036 \\
\hline 69 & 0.506 & 408,360 & 0.325 & 321,455 & 0.646 & 81,827 & 0.467 & 63,616 & 0.426 & 0.568 & -0.142 \\
\hline \multirow[t]{2}{*}{70} & 0.493 & 408,360 & 0.312 & 321,455 & 0.505 & 53,669 & 0.412 & 44,092 & 0.413 & 0.463 & -0.050 \\
\hline & & & & & & & & & \multicolumn{2}{|l|}{ Meal } & -0.065 \\
\hline
\end{tabular}

Note: Sample includes all full-time male workers. Actual SRHS and population sample sizes are calculated using a pooled average of six waves of HRS data (2000-2010). Means and sample size frequencies are adjusted for complex sample design. Predicted SRHS is estimated from Eq. 6. Predicted population weighted mean is calculated using the the pooled sample size averages of HRS male respondents who report working full-time at age 61.

\section{Discussion}

This study uses a dynamic panel correlated random effects model to estimate the effect of current job demands on health and health disparities across occupations before retirement. Results show the major channel between working conditions and health at older ages is the degree of control and influence workers have on the job, which is associated with improved SRHS, cognitive function, and lower blood pressure, while physical demands and exposure to 
hazardous environmental conditions are not significant. Although the biological and social pathways between psychosocial job demands and health outcomes are not fully understood these findings indicate workers who have higher levels of control and influence on the job may be more insulated from stress and therefore healthier overall. For example, research has shown constant exposure to stress can alter the brain's biochemistry, causing chemical imbalances that set off a cascade of physiological responses and impact everything from sleeping patterns to how the body processes food (e.g. Juster and McEwen, 2014; Juster, McEwen, and Lupien, 2010; McEwen and Gianaros, 2010).

On the other hand, there is little evidence to suggest that working conditions account for observed health differences between occupations in later life-i.e. even after controlling for working conditions, white collar workers are still in significantly better health than blue collar or service workers, and these differences remain relatively fixed at older ages. In addition, the panel analysis confirms that there is strong persistence from baseline health, educational attainment, and mid-career earnings growth on self-reported health, cognitive function, and depression. These effects exert a stronger influence on health at older ages than current job demands, underscoring the potential durable impact of education and prior labor market experiences on later health.

Limitations of these analyses should be mentioned. Primarily, while results present fairly robust correlations between working conditions and health, there are several limitations that prevent a causal interpretation of the results. First, although evidence suggests attrition bias is minimal, and several steps are taken to minimize dropout, it is still possible that attrition due to poor health or the retirement decision could be biasing results. Second, this study can only evaluate the impact of current working conditions on health - i.e. the impact of job demands 
earlier in a worker's career cannot be assessed. Thus, it is possible physically demanding jobs or exposure to environmental hazards took their toll on worker health before age 50 and affect observed health differences between occupations at older ages. Third, although the model controls for historical trends in individual earnings, the consistent feedback loop between SES and health over the life course makes it difficult to isolate the cumulative impact of working conditions on health from contemporaneous effects.

Another significant limitation of this study is outcomes are explored for men only and therefore cannot speak to whether occupational segregation by gender or race further undercut health or differentially impact the occupational-health divide, despite evidence that low pay and hazardous working conditions tend to cluster by gender and race (e.g. Anker, 1998; England et al., 2002; Goldsmith et al., 2007; Reskin and Roos, 1990; Sokoloff, 2014). As a result, further research that incorporates quasi-experimental variation and/or data that can track workers across the life course and across various demographic populations would considerably buttress the findings reported in this study.

In terms of policy, results have implications for retirement age policies, labor force attachment at older ages, and the cost of retiree health care programs. In particular, model predictions reveal that due to the fixed nature of the occupational health gradient at older ages, policies that seek to extend the working life by increasing the normal retirement age for all workers may reduce overall population health. Adjusting the work environment at older ages may improve health outcomes to a degree, however results suggest interventions that promote health-enhancing aspects of the work environment earlier in the life course may have a stronger impact on future health and labor force participation. Early retirement, work disability claims, and unemployment costs due to poor health put enormous pressure on local, state, and federal 
government programs. To evaluate the sustainability of retiree health programs as well as the efficacy of policies geared towards encouraging labor force participation at older ages, further research on how working conditions across the life course are impacting health and labor force attachment at older ages is needed. 


\section{Appendix}

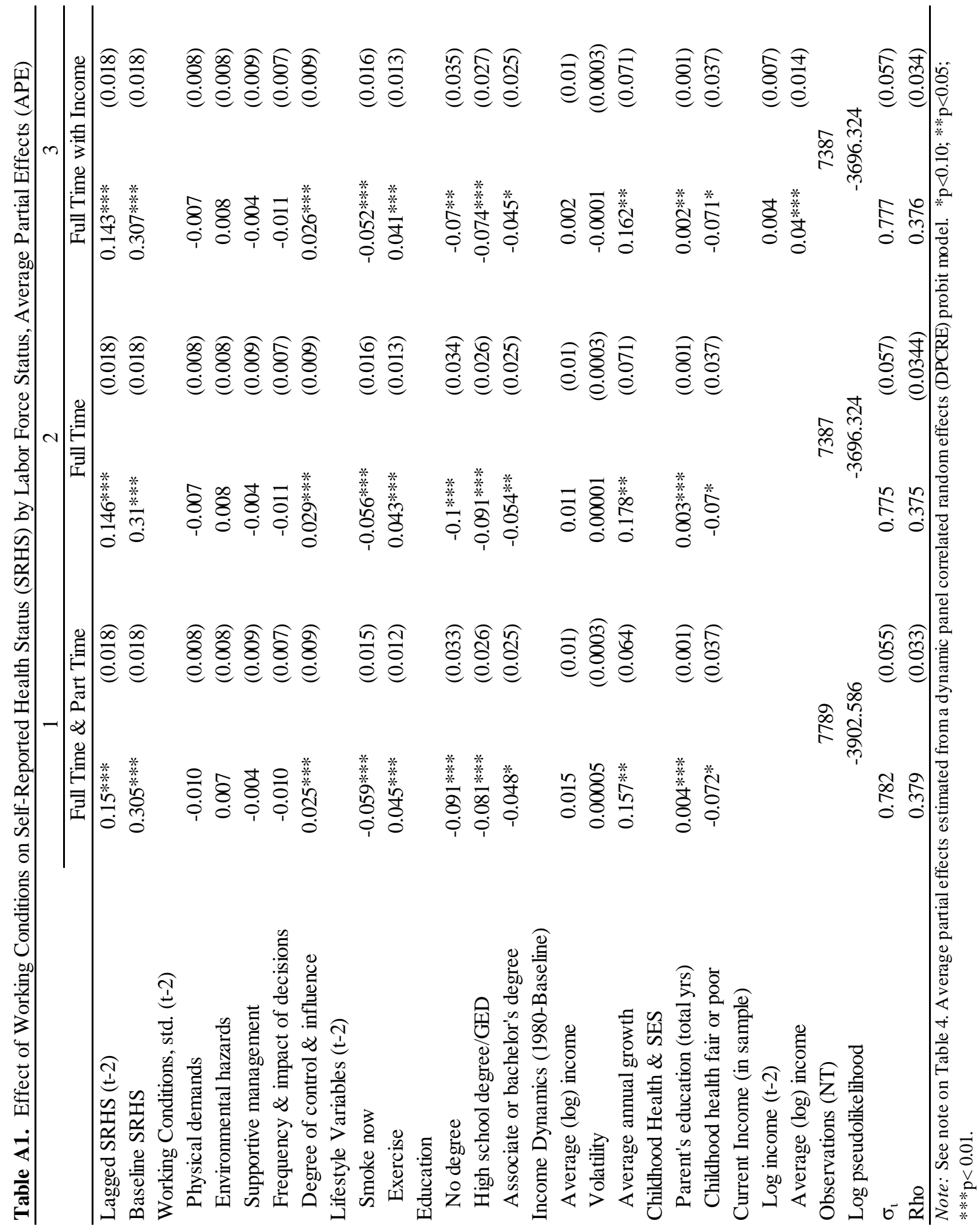


Figure A1. Kaplan-Meier Survivial Estimates by Occupational Status, Male Workers

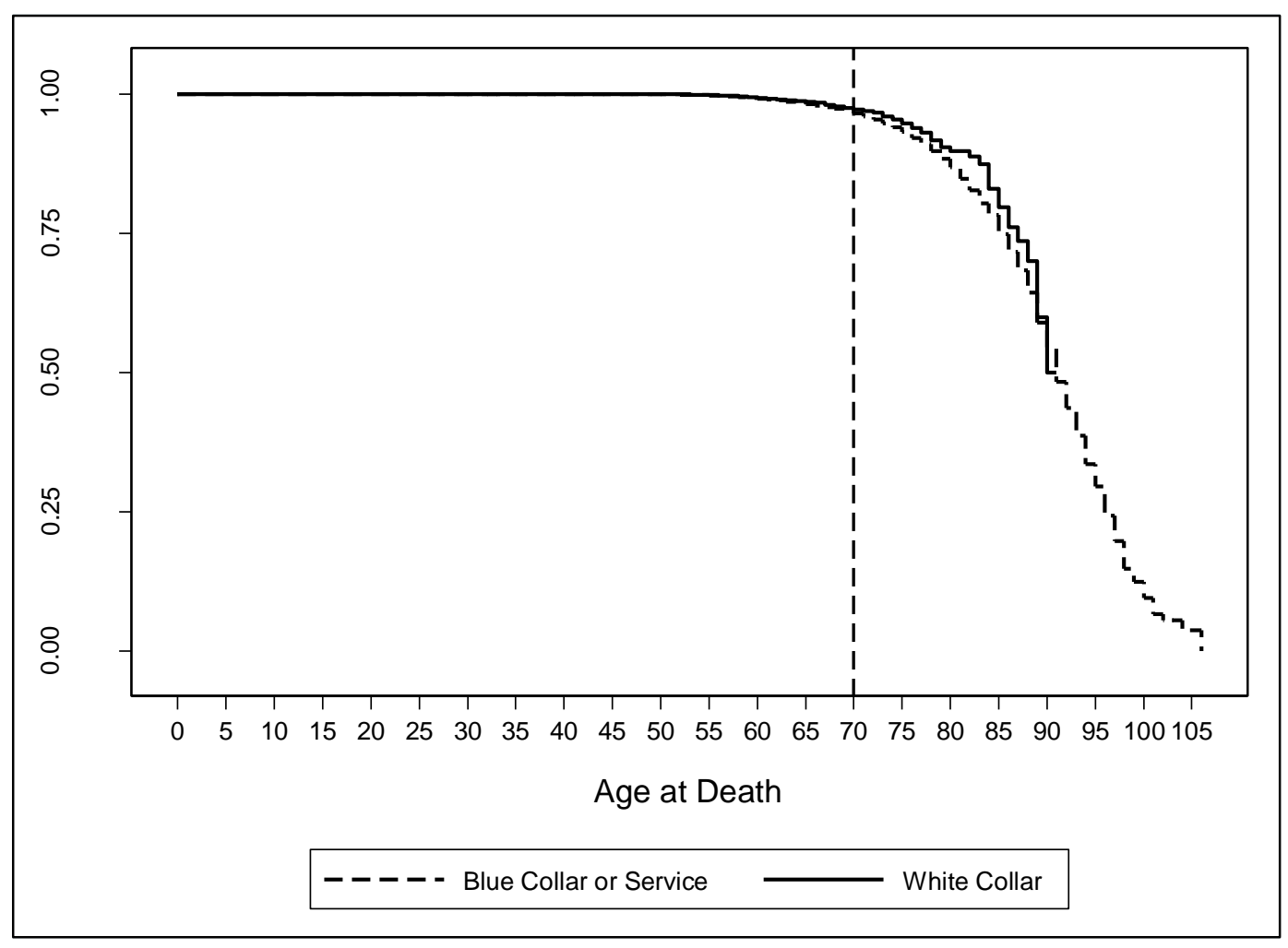

Note: Kaplan-Meier survival estimates were constructed from the full sample of male workers in the HRS between 1992 and 2010 (total number of deaths=4,864). 


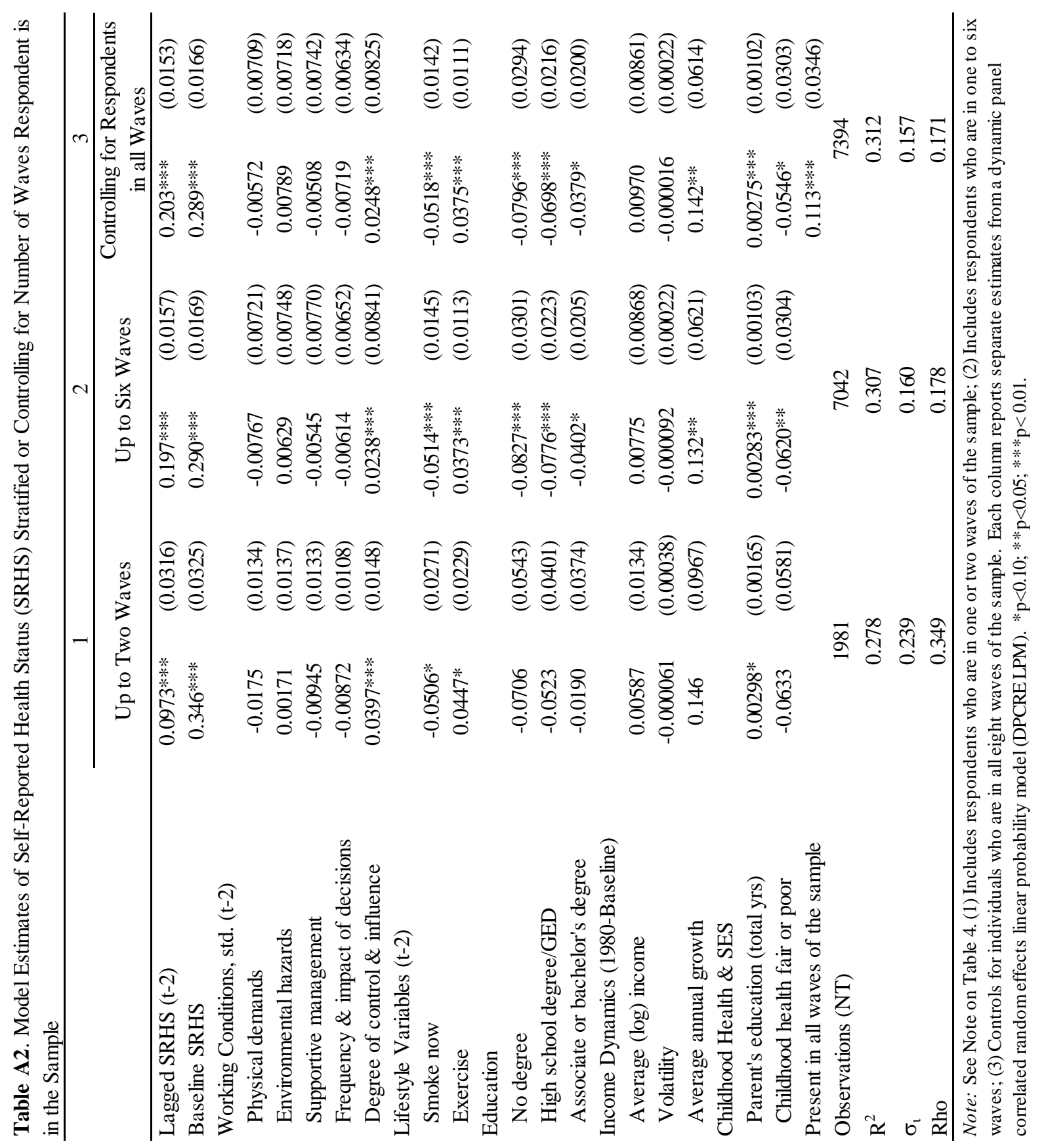




\section{References}

Aaron, Henry J. (2013). Nudged, Pushed, or Mugged: Policies to Encourage Older Workers to Retire Later. In Burtless, Gary, and Aaron, Henry J. (Eds.). (2013). Closing the Deficit: How Much Can Later Retirement Help? (pp. 72-89). Washington, D.C.: Brookings Institution Press.

Adams, Peter, Hurd, Michael D., McFadden, Daniel, Merrill, Angela, and Ribeiro, Tiago. (2003). Healthy, wealthy, and wise? Tests for direct causal paths between health and socioeconomic status. Journal of Econometrics, 112(1), 3-56.

Angrist, Joshua D., and Pischke, Jörn-Steffen. (2008). Mostly Harmless Econometrics: An Empiricist's Companion: Princeton University Press.

Anker, Richard. (1998). Gender and jobs: Sex segregation of occupations in the world. Geneva: International Labour Office.

Bosma, Hans, Marmot, Michael G., Hemingway, Harry, Nicholson, Amanda C., Brunner, Eric, and Stansfeld, Stephen A. (1997). Low job control and risk of coronary heart disease in Whitehall II (prospective cohort) study. BMJ: British Medical Journal, 314(7080), 558.

Boma, Hans, Peter, Richard, Siegrist, Johannes, and Marmot, Michael. (1998). Two alternative job stress models and the risk of coronary heart disease. American Journal of Public Health, 88(1), 68-74.

Bound, John, Brown, Charles, and Mathiowetz, Nancy. (2001). Measurement error in survey data. Handbook of Econometrics, 5, 3705-3843.

Bound, John, Stinebrickner, Todd, and Waidmann, Timothy. (2010). Health, economic resources and the work decisions of older men. Journal of Econometrics, 156(1), 106-129.

Burgard, Sarah. A., and Lin, Katherine. Y. (2013). Bad jobs, bad health? How work and working conditions contribute to health disparities. The American Behavioral Scientist, 57(8).

Card, David, Maestas, Nicole, and Purcell, Patrick J. (2014). Labor Market Shocks and Early Social Security Benefit Claiming. Michigan Retirement Research Center Research Paper No. WP, 317.

Case, Anne, and Deaton, Angus S. (2005). Broken down by work and sex: How our health declines. Analyses in the Economics of Aging (pp. 185-212): University of Chicago Press.

Case, Anne, and Paxson, Christina. (2011). The long reach of childhood health and circumstance: Evidence from the Whitehall II Study. The Economic Journal, 121(554), F183-F204.

Chao, Elaine L., and Utgoff, Kathleen P. (2003). The national compensation survey: Employee benefits in private industry in the United States, 2000. Washington, DC: US Department of Labor.

Cheng, Yawen, Kawachi, Ichiro, Coakley, Eugenie H, Schwartz, Joel, and Colditz, Graham. (2000). Association between psychosocial work characteristics and health functioning in American women: Prospective study. BMJ, 320(7247), 1432-1436.

Coile, Courtney C., Levine, Phillip B., and McKnight, Robin. (2012). Recessions, older workers, and longevity: How long are recessions good for your health?: National Bureau of Economic Research Working Paper.

Conti, Gabriella, Heckman, James, and Urzua, Sergio. (2010). The Education-Health Gradient. American Economic Review, 100(2), 234-238. 
Contoyannis, Paul, Jones, Andrew M., and Rice, Nigel. (2004). The dynamics of health in the British Household Panel Survey. Journal of Applied Econometrics, 19(4), 473-503.

Cottini, Elena, and Lucifora, Claudio. (2013). Mental health and working conditions in Europe. Ind. and Lab. Rel. Rev., 66, 958-989.

Cunha, Flavio, and Heckman, James. (2007). The Technology of skill formation. American Economic Review, 97(2), 31-47.

Currie, Janet, and Madrian, Brigitte C. (1999). Health, health insurance and the labor market. Handbook of Labor Economics, 3, 3309-3416.

Currie, Janet. (2009). Healthy, wealthy, and wise: Socioeconomic status, poor health in childhood, and human capital development. Journal of Economic Literature, 47(1), 87122.

Currie, Janet, and Almond, Douglas. (2011). Human capital development before age five. Handbook of Labor Economics, 4, 1315-1486.

Cutler, David M., and Lleras-Muney, Adriana. (2010). Understanding differences in health behaviors by education. Journal of Health Economics, 29(1), 1-28.

Cutler, David M., Lleras-Muney, Adriana, and Vogl, T. (2011). Socioeconomic status and health: Dimensions and mechanisms. In S. Glied and P. C. Smith (Eds.), Oxford Handbook of Health Economics. Oxford, U.K.: Oxford University Press.

Dahl, Molly, DeLeire, Thomas, and Schwabish, Jonathan A. (2011). Estimates of year-to-year volatility in earnings and in household incomes from administrative, survey, and matched data. Journal of Human Resources, 46(4), 750-774.

Dias, Pedro R., and O'Donnell, Owen. (Eds.). (2013). Health and Inequality (Vol. 21). Bingley, UK: Emerald Group Publishing.

Dobkin, Carlos, and Shabani, Reza. (2009). The health effects of military service: Evidence from the Vietnam draft. Economic Inquiry, 47(1), 69-80.

England, Paula, Budig, Michelle, and Folbre, Nancy. (2002). Wages of virtue: The relative pay of care work. Social Problems, 49(4), 455-473.

Falba, Tracy, Teng, Hsun- Mei, Sindelar, Jody L, and Gallo, William T. (2005). The effect of involuntary job loss on smoking intensity and relapse. Addiction, 100(9), 1330-1339.

Ferrie, J.E., Shipley, M.J., Smith, G. Davey, Stansfeld, S.A., and Marmot, M.G. (2002). Change in health inequalities among British civil servants: The Whitehall II Study. Journal of Epidemiology and Community Health, 56(12), 922-926.

Finkel, Deborah, Andel, Ross, Gatz, Margaret, \& Pedersen, Nancy L. (2009). The role of occupational complexity in trajectories of cognitive aging before and after retirement. Psychology and aging, 24(3), 563.

Fisher, Gwen G., Stachowski, Alicia, Infurna, Frank J., Faul, Jessica D., Grosch, James, \& Tetrick, Lois E. (2014). Mental work demands, retirement, and longitudinal trajectories of cognitive functioning. Journal of Occupational Health Psychology, 19(2), 231.

Fletcher, Jason M., Sindelar, Jody L., and Yamaguchi, Shintaro. (2011). Cumulative effects of job characteristics on health. Health Economics, 20(5), 553-570.

Gallo, William T., Bradley, Elizabeth H., Falba, Tracy A., Dubin, Joel A., Cramer, Laura D., Bogardus, Sidney T., and Kasl, Stanislav V. (2004). Involuntary job loss as a risk factor for subsequent myocardial infarction and stroke: Findings from the Health and Retirement Survey. American Journal of Industrial Medicine, 45(5), 408-416.

Gallo, William T., Bradley, Elizabeth H., Siegel, Michele, and Kasl, Stanislav V. (2000). Health effects of involuntary job loss among older workers findings from the Health And 
Retirement Survey. The Journals of Gerontology Series B: Psychological Sciences and Social Sciences, 55(3), S131-S140.

Goldsmith, Arthur H., Hamilton, Darrick, and Darity, William. (2007). From dark to light: Skin color and wages among African-Americans. Journal of Human Resources, 42(4), 701738.

Groot, Wim. (2000). Adaptation and scale of reference bias in self-assessments of quality of life. Journal of Health Economics, 19(3), 403-420.

Grossman, Michael. (1972). On the concept of health capital and the demand for health. The Journal of Political Economy, 80(2), 223-255.

Gueorguieva, Ralitza, Sindelar, Jody L., Falba, Tracy A., Fletcher, Jason M., Keenan, Patricia, Wu, Ran, and Gallo, William T. (2009). The impact of occupation on self-rated health: Cross-sectional and longitudinal evidence from the Health And Retirement Survey. The Journals of Gerontology Series B: Psychological Sciences and Social Sciences, 64(1), 118-124.

Gupta, Nabanita Datta, and Kristensen, Nicolai. (2008). Work environment satisfaction and employee health: Panel evidence from Denmark, France and Spain, 1994-2001. The European Journal of Health Economics, 9(1), 51-61.

Heckman, James. (1997). Instrumental variables: A study of implicit behavioral assumptions used in making program evaluations. Journal of Human Resources, 441-462.

Hurd, Michael D., Smith, James P., and Zissimopoulos, Julie M. (2004). The effects of subjective survival on retirement and social security claiming. Journal of Applied Econometrics, 19(6), 761-775.

Idler, Ellen L., and Benyamini, Yael. (1997). Self-rated health and mortality: A review of twenty-seven community studies. Journal of Health and Social Behavior, 21-37.

Ilmarinen, Juhani, and Rantanen, Jorma. (1999). Promotion of work ability during ageing. American Journal of Industrial Medicine, 36(S1), 21-23.

Ilmarinen, Juhani, Tuomi, Kaija, Eskelinen, Leena, Nygård, Clas-Håkan, Huuhtanen, Pekka, and Klockars, Matti. (1991). Summary and recommendations of a project involving crosssectional and follow-up studies on the aging worker in Finnish municipal occupations (1981-1985). Scandinavian Journal of Work, Environment and Health, 135-141.

Johnson, Richard W. (2007). Employment at older ages and the changing nature of work.

Jones, Andrew M., Rice, Nigel, d'Uva, Teresa Bago, and Balia, Silvia. (2013). Applied Health Economics. New York, NY: Routledge.

Jürges, Hendrik. (2007). True health vs response styles: Exploring cross- country differences in self- reported health. Health Economics, 16(2), 163-178.

Juster, Robert-Paul, and McEwen, Bruce S. (2014). Sleep and chronic stress: New directions for allostatic load research. Sleep Medicine.

Juster, Robert-Paul, McEwen, Bruce S., and Lupien, Sonia J. (2010). Allostatic load biomarkers of chronic stress and impact on health and cognition. Neuroscience and Biobehavioral Reviews, 35(1), 2-16.

Karasek, R., and Theorell, T. (1990). Healthy Work: Stress, Productivity and The Reconstruction of Working Life: Basic Books.

Kelly, Inas Rashad, Dave, Dhaval M., Sindelar, Jody L., and Gallo, William T. (2011). The impact of early occupational choice on health behaviors. Review of Economics of the Household, 1-34. 
Lancaster, Tony. (2000). The incidental parameter problem since 1948. Journal of Econometrics, 95(2), 391-413.

Levenstein, Susan, Smith, Margot W., \& Kaplan, George A. (2001). Psychosocial predictors of hypertension in men and women. Archives of Internal Medicine,161(10), 1341-1346.

Lleras-Muney, Adriana. (2005). The relationship between education and adult mortality in the United States. The Review of Economic Studies, 72(1), 189-221.

Mackenbach, Johan P., Stirbu, Irina, Roskam, Albert-Jan R., Schaap, Maartje M., Menvielle, Gwenn, Leinsalu, Mall, and Kunst, Anton E. (2008). Socioeconomic inequalities in health in 22 European countries. New England Journal of Medicine, 358(23), 2468-2481.

Markovitz, Jerome H., Matthews, Karen A., Whooley, Mary, Lewis, Cora E., \& Greenlund, Kurt J. (2004). Increases in job strain are associated with incident hypertension in the CARDIA Study. Annals of Behavioral Medicine, 28(1), 4-9.

Marmot, Michael G., Stansfeld, S, Patel, C., North, F, Head, J, White, I, . . Smith, G Davey. (1991). Health inequalities among British civil servants: The Whitehall II study. The Lancet, 337(8754), 1387-1393.

Marmot, Michael G., and Smith, George Davey. (1997). Socio-economic differentials in health. Journal of Health Psychology, 2(3), 283-296.

Marmot, Michael G., Ryff, Carol D., Bumpass, Larry L., Shipley, Martin, and Marks, Nadine F. (1997). Social inequalities in health: Next questions and converging evidence. Social Science and Medicine, 44(6), 901.

McEwen, Bruce S., and Gianaros, Peter J. (2010). Central role of the brain in stress and adaptation: Links to socioeconomic status, health, and disease. Annals of the New York Academy of Sciences, 1186(1), 190-222.

McWilliams, J. Michael, Meara, Ellen, Zaslavsky, Alan M., and Ayanian, John Z. (2007). Health of previously uninsured adults after acquiring Medicare coverage. JAMA, 298(24), 28862894.

Meyer, Peter B., and Osborne, Anastasiya M. (2005). Proposed category system for 1960-2000 Census occupations: US Department of Labor, Bureau of Labor Statistics, Office of Productivity and Technology.

Morefield, Brant, Ribar, David C., and Ruhm, Christopher. J. (2012). Occupational status and health transitions. The BE Journal of Economic Analysis and Policy, 11(3), 1-27.

Neuman, Kevin. (2008). Quit your job and get healthier? The effect of retirement on health. Journal of Labor Research, 29(2), 177-201.

Nizalova, Olena Y, and Murtazashvili, Irina. (2012). Exogenous treatment and endogenous factors: Vanishing of omitted variable bias on the interaction term. Journal of Econometric Methods.

Potter, Guy G., Helms, Michael J., \& Plassman, Brenda L. (2008). Associations of job demands and intelligence with cognitive performance among men in late life. Neurology, 70 (19 Part 2), 1803-1808.

Ravesteijn, Bastian, van Kippersluis, Hans, and van Doorslaer, Eddy. (2013). The contribution of occupation to health inequality. In P. R. Dias and O. O'Donnell (Eds.), Health and Inequality (pp. 311-334). Bingley, UK: Emerald Group Publishing Limited.

Reskin, Barbara F., and Roos, Patricia A. (1990). Job Queues, Gender Queues: Explaining Women's Inroads Into Male Occupations. Philadelphia, PA: Temple University Press. 
Robone, Silvana, Jones, Andrew M., and Rice, Nigel. (2011). Contractual conditions, working conditions and their impact on health and well-being. The European Journal of Health Economics, 12(5), 429-444.

Rosen, Sherwin. (1986). The theory of equalizing differences. Handbook of Labor Economics, 1 , 641-692.

Ruhm, Christopher J. (2000). Are recessions good for your health? The Quarterly Journal of Economics, 115(2), 617-650.

Smith, James P. (2007). The impact of socioeconomic status on health over the life-course. Journal of Human Resources, 42(4), 739-764.

Smith, James P. (2009). The impact of childhood health on adult labor market outcomes. The Review of Economics and Statistics, 91(3), 478-489.

Smith, James P., and Kington, Raynard. (1997). Demographic and economic correlates of health in old age. Demography, 34(1), 159-170.

Sokoloff, Natalie J. (2014). Black Women and White Women in the Professions: Occupational Segregation by Race and Gender, 1960-1980. New York, NY: Routledge.

Strully, Kate W. (2009). Job loss and health in the US labor market. Demography, 46(2), 221246.

Sullivan, Daniel, and Von Wachter, Till. (2009). Job displacement and mortality: An analysis using administrative data. The Quarterly Journal of Economics, 124(3), 1265-1306.

Tiffin, Paul A., Pearce, Mark S., and Parker, Louise. (2005). Social mobility over the lifecourse and self reported mental health at age 50: Prospective cohort study. Journal of Epidemiology and Community Health, 59(10), 870-872.

Tuomi, Kaija, Huuhtanen, Pekka, Nykyri, Erkki, and Ilmarinen, Juhani. (2001). Promotion of work ability, the quality of work and retirement. Occupational Medicine, 51(5), 318-324.

Tuomi, Kaija, Ilmarinen, Juhani, Seitsamo, Jorma, Huuhtanen, Pekka, Martikainen, Rami, Nygård, Clas-Håkan, and Klockars, Matti. (1997). Summary of the Finnish research project (1981-1992) to promote the health and work ability of aging workers. Scandinavian Journal of Work, Environment and Health, 66-71.

Van Kippersluis, Hans, O'Donnell, Owen, and van Doorslaer, Eddy. (2011). Long-run returns to education: Does schooling lead to an extended old age? Journal of Human Resources, 46(4), 695-721.

Verbeek, Marno, and Nijman, Theo. (1992). Testing for selectivity bias in panel data models. International Economic Review, 681-703.

Warren, John Robert, Hoonakker, Peter, Carayon, Pascale, and Brand, Jennie. (2004). Job characteristics as mediators in SES-health relationships. Social Science and Medicine, 59(7), 1367-1378.

Wiernik, Emmanuel, Pannier, Bruno, Czernichow, Sebastien, Nabi, Hermann, Hanon, Olivier, Simon, Tabassome, ... \& Danchin, Nicolas. (2013). Occupational status moderates the association between current perceived stress and high blood pressure evidence from the IPC Cohort Study. Hypertension, 61(3), 571-577.

Wilkinson, Richard G., and Pickett, Kate E. (2009). Income inequality and social dysfunction. Annual Review of Sociology, 35, 493-511.

Wooldridge, Jeffrey M. (2005). Simple solutions to the initial conditions problem in dynamic, nonlinear panel data models with unobserved heterogeneity. Journal of Applied Econometrics, 20(1), 39-54.

Zacher, Hannes. (2015). Successful aging at work. Work, Aging and Retirement, 1(1), 4-25. 